\title{
Savannah River Site Patented Technologies Summaries
}

by

D. E. Rabold

Westinghouse Savannah River Company

Savannah River Site

Aiken, South Carolina 29808

A document prepared for HOME PAGE

\section{DOE Contract No. DE-AC09-89SR18035}

This paper was prepared in connection with work done under the above contract number with the U.S.

Department of Energy. By acceptance of this paper, the publisher and/or recipient acknowledges the U.S. Government's right to retain a nonexclusive, royalty-free license in and to any copyright covering this paper, along with the right to reproduce and to authorize others to reproduce all or part of the copyrighted paper.

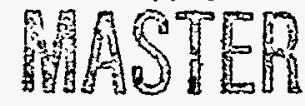




\section{DISCLAIMER}

This report was prepared as an account of work sponsored by an agency of the United States Government. Neither the . United States Government nor any agency thereof, nor any of their employees, makes any warranty, express or implied, or assumes any legal liability or responsibility for the accuracy, completeness, or uscfulness of any information. apparatus, product, or process disclosed, or represents that its:use would not infringe privately owned rights. Reference hercin to any specific commercial product, process. or service by trade name, trademark, manufacturer, or otherwise does not necessarily constitute or imply. its endorsement, recommendation, or favoring by the United States Government or any agency thereof. The views and opinions of authors expressed herein do not necessarily state or reflect those of the United. States Government or any agency: thereof.

This report has been reproduced directly from the best available copy.

Available to DOE and DOE contractors from the Office of Scientific and Technical Information. P. O. Box 62, Oak Ridge. TN 37831: prices available from (615) $576-8401$.

Available to the public from the National Technical Information Service, U. S. Department of Commerce, 5285 Port Royal Rd.. Springfield, VA 22161. 


\section{DISCLAIMER}

Portions of this document may be illegible in electronic image products. Images are produced from the best available original document. 
Title:

Application :

Advantages :

Abstract :

1

Status :

Reference \#:

Contact:
In-Situ Remediation System and Method for Contaminated Ground water

Environmental Remediation

A system for removing volatile contaminants from a subsurface plume of contamination comprising two sets of wells, a well for injecting a fluid into a saturated zone. on one side of the plume and an extracting well for collecting the fluid together with volatilized contaminant from the plume on the other side of the plume. The fluid enables the volatile contaminants to be volatilized and carried therewith through the ground to the extracting well. Injecting and extracting wells are preferably horizontal wells positioned below the plume in the saturated zone and above the plume in the vadose zone, respectively. The fluid may be air or other gas or a gas and liquid mixture depending on the type of contaminant tc be removed and may be preheated to facilitate volatilization. Treatment. of the volatilized contaminatic may be by filtration, incineration, atmospheric dispersion or the like.

- Patent

SRS-88-0001

Iicensing Representative Westinghouse Savannah River Company Cooperative Research Center 227 Gateway Drive Aiken, SC 29803 $1-800-228-3843$ 
Title:

Application:

Advantages :

Abstract :

Status :

ireference \#

Contact :
Leak Detection Aid

other: Industrial
A leak detection apparatüs and method for detecting leaks across an o-ring sealing a flanged surface to a mating surface is an improvement in a flanged surface comprising shallow groove following o-ring in communication with an entrance and exit port intersecting the shallow groove for injecting and withdrawing, respectively, a leak detection fluid, such as helium: A small quantity. of helium injected into the entrance port will flow to the shallow, groove, past the o-ring and to the exit port.

\section{Patent}

SRS-88-00019

Lic̀ensing Representative Westinghouse Savannah River Company Cooperative Research center 227 Gateway Drive

Aiken, SC 29803

$1-800-228-3843$ 
Titie:

Application:

Advantages :

Abstract:
Aerobic Microorganism for the Degradation of Chlorinated Aliphatic Hydrocarbons

Environmental Remediation
A chlorinated aliphatic hydrocarbon-degrading microorganism, having American Type Culture Collection accession numbers ATCC 53570 and 53571, in a biologically pure culture aseptically collected from a deep subsurface habitat and enhanced, mineralizes trichloroethylene and. tetrachloroethylene to $\mathrm{HC1}, \mathrm{H} 2 \mathrm{O}$ and $\mathrm{CO} 2$ under aerobic. conditions stimulated by methane, acetate, methanol; tryptone-yeast extract, propane and propane-methane.

\section{Status:" : Patent}

Reference \#:

Contact:
SRS-88-0024

Iicensing Representative Westinghouse Savannah' River Company Cooperative Research Center. 227. Gateway Drive. :

Aiken, SC 29803

$1-800-228-3843$ 
Title:

Application:

Advantages :

Abstract:

Status :

Reference \# :

Contact:
Precipitate Hydrolysis Process for the Removal of Organic Compounds from Nuclear Waste Slurries

Environmental Remediation

A process for removing organic compounds from a nüclear. waste slurry comprising reacting a mixture of radioactive waste precipitate slurry and an acid in the presence of a catalytically effective amount of a copper (II) catalyst whereby the organic compounds in the precipitate slurry. ar hydrolyzed to form volatile organic compounds which are. separated from the reacting mixture. The resulting waste slurry, containing less than 10 percent of the original. organic compounds; is subsequently blended with high level radioactive sludge and transferred to a vitrification facility for processing into borosilicate glass for long-term storage.

Patent

SRS-88-0046

Licensing Representative

Westinghouse Savannah River Company

Cooperative Research Center

227 Gateway Drive

Aiken, SC 29803

$1-800-228-3843$ 
Title:

Application:

Advantages :

Abstract :

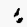

Status :

Reference \#:

Contact:

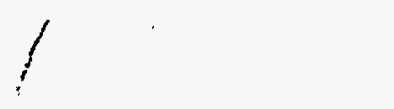

Expandable Pipe Crawler

Robotics and Remote Sysțems
A pipe crawler having a front leg assembly and a back leg. assembly connected together by two air cylinders, each leg assembly having four extendible legs and a pair of actuators for sliding the extendible legs radially outward to increase the range of the legs when the pipe crawler enters a section of pipe having a larger diameter. The crawler crawl's by "inchworm"-like motion, the front leg assembly and back leg assembly alternately engaging and disengaging the wall of the pipe to hold the pipe crawler as the air cylinders alternately advance the front leg assembly and bring up the rear leg assembly. The pair of actuators of each leg assembly are parallel; adjacent. and. opposing acting so that each slides two adjacent extendible legs, radially outward.

Patent

SRS-88-0002

Licensing Representative Westinghouse Savannah River Company Cooperative Research Center. 227 Gateway Drive

Aiken, SC 29803

$1-800-228-3843$ 
Title:

Application:

Advantages:

Abstract :

/ status:

Reference \#:

Contact :
Analog Graphic Display Method, and Apparatus

Other: Industria?.
A method for improving the resolution and readability of LED bar graph displays by superimposing a modulating AC wave form on either the input or the reference signal, causing each display element to flash at a visible rate with variable duty cycle representing the input value within a narrow range while acting in a conventional mannes (steadily on or off) when the input is outside this range. The invention includes a novel modulating wave form. especially well-suited to this purpose, a simple technique for generating it, and methods for applying it to common integrated-circuit display drivers having both linear and logarithmic responses.

Patent

SRS $-88-0003$

Iicensing Representative

Westinghouse Savannah River Company. Cooperative Research Center

227 Gateway Drive

Aiken, SC 29803

$1-800-228-3843^{\circ}$ 
Tittle:

Application:

Advantagies :

Abstract:

\section{Status :}

Referençe \#:

Contact:
"In-Line" Rotating Torque Sensor with On-Board Amplifier Sensors

A mechanical and electronic technique for measuring verý small torques developed along a rotating mechanical assembly when extraneous force, elastic flexing and/or mechanical noise must be minimized.

\section{Patent}

SRS-88́-0005.

Licensing Representative : Westinghouse Savainnah. River Company Cooperative Research Center

227 Gateway Drive Aikèn, SC 29803

$1-800-228-3843$. 
Title:

Application:

Advantages :

Abstract:

Status:

Reference \#: contact :
Stimulatory Activity of Trichlorethylene for Positive Chemotaxis by Bacteria

Environmental Remediation

Trichlorethylene was" discovered to strongly. promote positive chemotaxis in soil bacteria at very'low concentrations. This discovery has potential application to promote movement of bacteria towards a substance for th purpose of degradation or towards a'substance that is toxi to the bacteria.

Patent

SRS-88-0006

Iicensing Representatïve Westinghouse Savannah River Company Cooperative Research .Center. 227. Gateway Drive

Aiken, SC 29803

$1-800-228-3843$ 
Title:

Application:

Advantages :

Abstract :
Mixing Blade Assembly for Gel-Strength Testing

Other: Industrial

A blade assembly for gel-strength testing, consisting of a shaft bearing a plurality of blades each having a different geometry, which minimizes mechanical disturbance of the mix? and discourages the development of shear zones which can cause falsely low gel-strength readings:

status :

Patent

Reference \#:

SRS $-88-0007$

Contact :

Licensing Representative:

Westinghouse Savannah River Company Cooperative Research Center

227 Gateway Drive

Aiken, SC 29803

$1-800-228-3843$

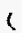


Title:

Application:

Advantages :

Abstract:

Status:

Reference \#

Contact:
Method for Thermal Processing Alumina-Enriched Spinei Single Crystans

Other: Materials Science
The invention relates to a method for thermally processing alumina-rich spinel crystals to obtain desired physical. characteristicis.

Patent

$\mathrm{SRS}-88=0.016$

Iicensing Representative.

Westinghouse Savannah River Company

Cooperative Research Center:

227 Gateway Dirive:

Aiken, SC 29803

$1-800-228-3843$ 
Title:

Appiication:

Advantages:

Abstract :

statús:'

Reference \#:

Contact:

\section{In-Situ Spectrophotometric Probe}

Senșors
A probe using fiber optic fibers, a glass lens-cylinder, and a mirror grid to transmit light from a source through very. small amount of liquid and then to a measuring device

Patent

SRS-88-0008

Licensing Representative Westinghouse Savannah River: Company Cooperative Research Center

227 Gateway Drive

Aiken, SC 29803

$1-800-228-3843$ 
Title:

Application:

Advantages :

Abstract :

Status :

Reference \#:

Contact :
Self-Referencing, spectrophotometric Meásurements

Sensors

A translucent material with an affinity for the compound c' interest is exposed to light. : The compound-material complex photolytes to produce species with a different absorption spectrum. By monitoring the change in absorption as a function of time, compound concentration can be monitored.

Patent

SRS $-88-0009$

Licensing Representative Westinghouse Savannah River Company -Cooperative Research Center 227 Gateway Drive Aiken, SC 29803

$1-800-228-3843$ 
Title:

Application:

Advantages :

Abstract :

Status :

Ŕeference \#:

Contact:
Self-Referencing Remote Optical Probe.

Sensors

This invention relates to devices used for taking. spectrophotometric measurements remoteiy. It comprises a probe for optical absorption measurements of fluid and gas samples. The probe has a sliding, reflecting plug inside, a lens at one end, ports for admitting and expelling the sample, and a means for.moving the reflecting plug toward and away from the lens. . Light is carried to the probe frc a light source and away from the probe to a spectral detector via fiber optic cạbles.

\section{Patent}

SRS-88-0010

Licensing Representative Westinghouse Savannah River Company Cooperative Research Center

227 : Gateway Drive

Aiken, SC 29803

$1-800-228-3843$ 
Title:

Porcelain Enamel Neutron Ạbsorbing Material

Application: $\cdot$ Other: Material Science

Advantages :

Abstract :

A porcelain enamel composition as a neutron absorbing material can be prepared of a major proportion by weight of a cadmium compound and a minor proportion of compounds of boron, lithium and silicon. These compounds in the form of a porcelain enamel coating or layer on several alloys has been found to be particularly effective in enhancing the. nuclear safety of equipment for use in the processing and storage of fissile material. The composition of the

$\therefore$ porcelain enamel coating can be tailored to match the coefficient of thermal expansion of the equipment to be coated and excellent coating adhesion can be'achieved.

\footnotetext{
Status:

Contact:
}

Patent

Reference \#:

SRS $-88-0.012$

Licensing Representative

Westinghouse Savannah River. Company

Cooperative Research Center

227 Gateway Drive

Aiken, SC 29803

$1-800-228-3843$ 
Title:

Application:

Advantages :

Abstract:

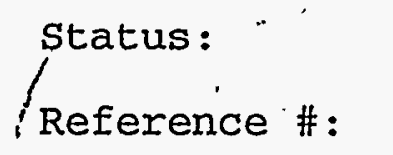

Contact:

Abstract:
"Smart" Watchoog Safety Switch

Other: Consumer Products

The safety switch is an electronic device that . automatically shuts down critical process equipment or process control equipment in the event of a system malfunction.
An electronic device, or "smart switch"; which monitors transitions in electronic process equipment control or output signals and provides automatic shutdown of critical devices in" case of failure. The switch is "smart" in that it accepts all. signal types and formats in common use, while rejecting most noise signals. Thus, it. is usable in $\therefore$ a wide variety of laboratory and process applications.
Patent

SRS-88-0013

Licensing Representativie Westinghouse Savannah River Company Cooperative Research Center 227 Gateway Drive

Aiken, SC $\cdot 29803$

$1-800-228-3843$. 
Title:

Āpplication:

Advantages :

Abstract:

Status:

i Reference \#:

Contact:
Collar Nut and Thrust Ring

Other: Industrial
A cap nut and thrust ring for use in sealing the waste tank pump shaft. The cap nut and thrust ring comprise a disk having a hole for the shaft; an o-ring between the nut and the shaft, a longitudinal flange at.the extreme radius of the disk with internal, very fine threads, a bearing at an interior radius of the. cap nut for urging the thrust ring against a graphite o-ring: as the cap is tightened to the', seal housing. The important features of the Lowery cap nu and thrust ring are the o-ring in the cap nut, the fine threads and the thrust ring.

Patent

SRS $-88-0015$

Licensing Representative Westinghouse Savannah River Company Cooperative Research Center 227 Gateway Drive

Aiken; SC 29803

1-800-228-3843 
Title:

Application :

Advantages :

Abstract :

Status :

Reference \#:

Contact:
Small Volume Sample Transfer Pump

Other: Industrial

A piston sample pump has not been used before because of leakage of the gas around the piston seal and the force required to move the piston against the force of the vacuu on the other side where the sample is drawn. However, by. maintaining a high vacuum on the back of the piston, the force required to move it is greatly reduced and the 0 -rin seal around it effectively seals against contamination.

The Small Volume Sample Pump is an improvement on the Toepler pump concept. Its purpose is to transfer minute quantities of sample without contamination: The pump has demonstrated the capability to transfer in excess of $90 \%$ c a sample consisting of as little as 10 to the -15 std cc.c sample. The Toepler pump, which is described in attachmen 1 , uses mercury to displace the sample. The Small Volume Sample pump displaces the sample by the motion of a piston manufactured from a metal appropriate for the sample, in this case stainless steel.' An extremely high vacuum is maintained on the side of the piston opposite the sample. It is the presence of this vacuum which makes it possible for a simple o-ring seal to prevent sample contamination. This vacuum also permits actuation of the piston (atmospheric pressure would exert in excess of 150 pounds of force on the piston).

Patent

SRS-88-0014

Licensing Representative

Westinghouse Savannah River Company

Cooperative Research Center

227 Gateway Drive

Aiken, SC 29803

$1-800-228-3843$ 
Title:

Application:

Advantages :

Abstract:
Multiple Forearm Robotic Elbow Configuration

Robotics and Remote Systems.

A dual forearmed robotic elbow configuration comprises a -main arm having a double elbow from which two coplanar forearms deperd, two actuators carried in the double elbow for moving the forearms, and- separate, independent end effectors, operated by a cable carried from the main arm through the elbow, is attached to the distal end of each

$\because$ forearm. Coiling the cables around the actuators prevents bending or kinking when the forearms are rotated 360 degrees... The end effectors can have similar or different capabilities. Actuator canisters within the dual elbow are modular for rapid replacement or maintenance. Coarse and fine resolver transducers within the actuators provide accurate position réferencing information.

Patent

Status :

SRS-88-0018

Reference \#:

Contact:

Licensing Representative Westinghouse Savannah River Company Cooperative Research Centier

227 Gateway Drive

Aiken, SC 29803

$1-800-228-3843$ 
Title:

Application:

Advantages :

Abstract:

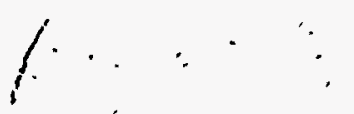

Status :

Reference \#:

Contact: :
Wave Guide Impedance Matching Method and Apparatus

other: Industrial

In the field of acoustics, it is important for efficient transmission of sound waves from a. wave guide into free aik to put an impedance matching device between the guide and the air. The device is usually a horn, with an exponential horn, being preferred. In some applications there is no space for a horn attachment. - The invention here is a. method for changing the shape of the end of the wave guide so that the impedance matching occurs without the addition of a horn. The technique or method comprises the cutting of a plurality of lengthwise slits in the periphery of the guide. The width of the slits increases toward the end of the guide so that, at the end of the guide, the slits. predominate and the remaining peripheral portions of the guide are reduced to points. The guide thus looks like a "crown". that has a large height to diameter ratio. This technique is advantageous for uiltrasonic and microwave frequencies such as used in cooking and communication transmission.

\section{Patent}

SRS-88-0021:

Licensing Representative Westinghouse Savañnah River Company Cooperative Research Center 227 Gateway Drive Aiken, SC 29803 $1-800-228-3843$ 
Title:

Application:

Advantages :

Abstract :

Status :

Reference \#:

Contact:
Surface Mount Component Jib

Other: Tool Technologies
The invention is a jig for bending the wires issuing from the sides of an electrical circuit board surface component so that they can be soldered to the surface of a circuit board. Many components have wires that are made'long and. straight (like legs of insects) to extend through the boar. so that they can be soldered on the opposite side of the board. More recently, soldering to the same side 'of a : board has become useful as a space saving technique. To use the sáme components for surface mounting as for. penetration mounting, the leg-like wires must be bent outwardly at approximately. right angles so they are parallel with the board surface and the component, is sitting just above the board: The jig accomplishes this right angle bending in one continuous motion. "The bending process 'comprises inserting the component in a recess in' one side of the jig, and pressing that side down. onto the . second side of the jig. As the pressing continues, the ends of each wire are guided outwardly and at right angles to the balance of the: wire until the center of the second part of the jig compresses downward and inverts into a " $\mathrm{V}$ : shape. to allow a sharp, slight over bend. When the two. parts of the jig are separated and the component removed, the wire ends spring:back slightly. from the over bend to a right angle.

Patent

SRS-88-0020

Licensing Representative Westinghouse Savannah River Company Cooperative Research Center 227 Gateway Drive Aiken, SC 29803 $1-800-228-3843$ 
Title:

Application: ' Sensors

Advantages:

Abstract :

Status :

Reference \#:

icontact:

Patent
Self-Checking Liquid Level Sensor

A solid-state circuit driving a miniature glass-encased thermistor probe for liquid-level sensing, and providing. logic outputs for computer process monitoring or control. The circuit not only senses whether the thermistor is wet or dry, but also detects possible fault conditions (i:e:, thermistor broken or shorted). This providès a constant check on the functioning of probes located remotely or in hostile environments.

SRS $-88-0023$

Licensing Representative Westinghouse Savannah River Company Cooperative Research Center 227 Gateway Drive

Aiken, SC 29803

$1-800-228-3843$ 
Title:

Application:

Advantages:

Abstract:

Status:
Reference \#

Contact :
In-Situ Remediation System for Ground water and Soils usin Reactive Fluids

Environmental Remediation

Reactive fluids are injected into the soil through

horizontal wells positioned below or within the contaminated area... The fluids react with the contaminants to form non-hazardous products. These products either remain in the "soil, escape into the atmosphere, travel..wit the ground water; or degrade further. If the reactive flui is a toxic gás, a second horizontal well is positioned above the contaminated region in the vadose zone in order to collect the excess reactive fluid before it enters the atmosphere.

Patent

SRS- $-89-0024$

Licénsing Repŕsesentative'

Westinghouse Savannah River, Company

Cooperative Research Center.

227 Gateway. Drive

Aiken, SC 29803

$1-800-228-3843$ 
Title: $\cdot$ In-Line Rotating Capacitive Torque Sensor

Application: '' Sensors

Advantages :

Abstract :

A mechanical and electronic technique for measuring large or small torques developed along a rotating mechanical assembly while avoiding the problems of transmitting signal and, power between rotating and stationary sections.

Status: 'Pátent'

Reference \# : ', SRS-88-0038.

Contact:

Licensing Representative

Westinghouse Savannah River Company

Cooperative Research Center

227 Gateway Drive

Aiken, SC 29803

$1-800-228-3843$ 
Title:

Application:

Advantages :

Abstract :

Status:
Reference \#:

Contact:
Asynchronous Parallẹ Input Status Comparator

Other: Industrial

The Asynchronous Parallel. Input status Comparator(APISC) is a digital-integrated circuit, with multiport parallel. inputs and multiple outputs. This device mätches a selecte number $X$ of $Y$ parallel input ports, where $X$ is the number of ports required to match for an output and $Y$ is the tota number of input ports. The APISC provides a high speed.. comparison of digital values without a need for computers or software coding $\therefore$ This implementation on a single diè provides algorithm security; improved reliability, and reduced cost-when compared.to computer system or standard logic gate packages.

Patènt

SRS $-89-0003$

Licensing Representative Westinghouse Savannah River Company Cooperative Research Center 227 Gateway Drivé

Ajken, SC 29803

$1-800-228-3843$ 
Titlë:

Application:

Advantages :

Abstract :
Solid state Safety Jumper Cables

Other: Consumer Products
Status:

Reference \#:

Contact :
A battery jumper cable assembly for automatically assuring the safe:connection of two storage batteries in a parallel relationship for charging the batteries or starting a motc vehicle which has a dead battery. Digital solid-state logi is used to determine the polarity of each battery connecte to the cable, and ensure that neither battery is shorted; sealed relays or preferably solid state switches of a nove design (covered by a separate patent proposal) are then closed to permit charging current to flow. When all connections have been properly made, an indicator light glows to indicate charging is taking place. A manual switch permits charging to be interrupted if desired.

Patent

SRS-89-0005

Licensing Representative

Westinghouse Savannah River Company

Cooperative Research Center.

227 Gateway Drive

Aiken, SC 29803

$1-800-228-3843$ 
Title:

Application: . Other: Industrial

Advantages :

Abstract :

\section{- Status: \\ Reference \#: \\ Contact:}

Abstract:

Patent

SRS-89-0018

\section{Reverse Jet Cooler/Separator}

This invention modifies the existing film cooling method utilized in melter off-gas exhaust line applications by inserting reverse jets at the exhaust line entrance. The reverse jets direct cooling fiuid against the off-gas flow This creates a vortex. which prevents large feed materials (lesss than or equal to 50 microns) from escaping the melte plenum while also reducing at the off-gas line entrance by cooling the pipe inner wall surface.

Iicensing Representative Westinghouse Savannah :River Company Cooperative Research. Center 227 Gateway Drive

Aiken, SC 29803 $1-800-228-3843$ 
Title:

Application:

Advantages :

Abstract :

Status:

Contact :
Ion Exchange Mercury Removal From Contaminated Soil

Environmental Remediation

This, invention proposed to sorb mercury cations from the. , soil through the use of a hydrophilic polymer membrane impregnated with GT-73, a commercially available ion-exchange resin. - The impregnated membrane will be." buried in the ground where the spill occurred. The mercur cations will migrate to the resin coating and be sorbed. An electric current may be used to induce migration of ions. Hydrogen or sodium ions will be placed in the soil in exchange for the mercury cations. The polymer membrane will be removed and stored when the resin is depleted.

\section{Patent}

SRS-89-0021

Licensing Representative Westinghouse Savannah. River Company Cooperative Researçh Center

227 Gateway Drive

Aiken, SC 29803

$1-800-228-3843$ 
Title:

Application:

Advantages :

Abstract :

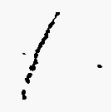

Status :

Reference \#:

Contact :
Plutonium Recovery through Microwave Leaching or Dissoluti

Other: Industrial

The invention is a new, rapid, less expensive method for recovering plutonium from materials with a porous nature a a result of having been incinerated or ashed in a high temperature furnace. It consists of the application of microwaves combined with immersion in a fluid to remove plutonium from the fragment into the fluid by selective leaching without dissolving the material. The choice of fluid used for immersion and the length of microwave application determine, whether recovery occurs by dissolution of the fragment or selective leaching. Anothe potential use is the application of an incineration process plus microwave leaching to remove other hazardous metals from porous'materials. A third potential use for the invention is a more efficient dissolution procedure using microwaves plus the same chemicals that are used in conventional methods, and.using sealed pressure vessels at elevated temperatures which further enhances the rate of chemical reaction.

Pátent

SRS $-89-0022$

Iicensing Representative Westinghouse Savannah River Company Cooperative Research Center 227 Gateway Drive

Aiken, SC 29803

$1-800-228-3843$ 
Title:

Application:

Advantages :

Abstract:

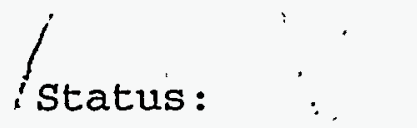

Reference \#:

Contact :
Solder for Oxide Layer-Building Metals and Alloys

Other: Materials Science

A solder for joining aluminum and similar "self-protecting metals and alloys to themselves or to other metals or alloys, producing a metallurgical bond with high mechanica strength and electrical conductivity. .under common "benchtop" soldering conditions. The solder is an alloy chiefly of tin and zinc. In roughly $2: 1$ ratio by weight, plus a small amount of germanium to serve as a wetting agent. Other metals, such as copper and antimony, may be added to harden and toughen the alloy. Particles of grit, such as silicon carbide, may also be blended mechanically into the alloy to aid in initial penetration of surface oxides.

\section{Pátent}

SRS-89-0026

Licensing Representatịve Westinghouse Savannah River Company Cooperative Research Center

227 Gateway Drive

Aiken, SC 29803

$1-800-228-3843$. 
Title:

Application:

Advantages :

Abstract:
Chemotactic Selection of Pollutant Degrading Soil Bacteria Environmentàl Remediation
$-$

The invention is a faster method for determining the spécific number of bacterial degraders for a particular chemical substance: 'It uses the characteristic called chemotaxis, the capability. of bacteria to move toward or away from chemicals. The technique involves the use of capillary tubës, which are filled with a.known chemical an placed into contaminated soil. After a period of time, the tubes are removed and examined for the number and types of bacteria. which enter the tubes from the soil. This technique requires less time than previous techniques, and is therefore useful for the isolation and selection of. contaminant degraders:

Patent

SRS-89-0027

Licensing Representative

Westinghouse Savannah River Company

Cooperative Research Center

227 Gateway. Drive

Aiken, SC 29803

$1-800-228-3.843$ 
Title:

Application:

Advantages :

Abstract: .

Nuclear Reactor Flow Control Method and Apparatus

Other: Industrial

The invention consists of a new design for a series of perforated universal sleeve housings (USHs), which are. located within the permanent tubes of reactor plenums and allow coolant to flow from the plenum inlet nozzle into th reactor assemblies. The purpose of this new USH design is to provide a more even distribution of coolant by divertin it toward the high power inner reactor assemblies during a Loss of Coolant Accident (IOCA), and at the same time allc for proper coolant flow during normal reactor operation. Thilis is accomplished by changing the number of rows of holes, the number of holes per row, the size of the holes,. and the elevation of the lowest row of holes on the USH above the plenum bottom. These alterations cause the USHs to act, for drained-tank emergency coolant conditions; in the same way as the orificing of assemblies under full-tan full-flow conditions.

Status :

Patent

Reference.\#:

SRS-89-0034.

Contact:

Licensing Representative Westinghouse Savannah River Company Cooperative Research Center 227 Gateway Drive

Aiken, SC 29803

$1-800-228-3843$ 
Title:

Application:

Advantages :

Abstract:

False Color Viewing Device

Other: Industrial

Other: Industrial

A viewing device, preferably taking the form of lightweigh goggles, and consisting of transparent filters combinied. wi.th means for excluding stray light from the eyes. The filters pass light in the near-infrared (beyond 750 nanometers), but block.all. light in the normally-visible spectrum except for a small amount in the blue-green region. The human eye has some sensitivity in the 750-800 nm band; this is usually masked by shorter-wavelength red light, but appears as. "deep red" when such light is blocked. The effect is to make visible'a región of the spectrum which normally goes unseen; this is the same spectral region which supplies the "red" channel in. infrared false-color photography. The brain combines the resulting blue-green and, deep-red images, yielding an imag in full color, but one' in which ordinary "red" perception has been exchanged for the near infrared. Many objects reflect light quite differently in these. two parts of the spectrum. Vegetation, for instance; reflects strongly in. "the near infrared and thus appears through the filter (as it does in false-color photography) in a range of red and purple tones which can reveal species distribution or, in single-species area; variations in health of the individua plants. The novelty of the invention is that infrared false-color viewing has previously required elaborate equipment, either electronic or photographic, and thus ha

Status :

Reference \#:

Contact :

\section{Patent -}

SRS-89-0047

Licensing Reprèsentative Westinghouse Savannah River company Cooperative Research Center

227 Gateway Drive

Aiken, SC 29803

$1-800-228-3843$ 
Title:

Application:

Advantages :

Abstract :

status :

Referencë \#:

Contact :
Compact Biomedical Pulsed Signal Generator for Bone Tissue Stimulation

Other: Biomedical' Applications

A compact, battery-powered circuit module which generates an electrical wave form consisting of an intermittent puls train simulating the piezoelectric response of human bone under stress. Electrical signals of this type have been shown to. accelerate bone growth, especially in the heating of fractures, and to prevent or reverse the development of osteoporosis; some acceleration in the heating of soft tissues has also been observed. While devices. generating these-signals have been used in medical treatment for several years, such devices are typically bulky, heavy, an very expensive: Because of high operating power, such device's are either line-powered or require heavy, rechargeable battery packs. High voltages may, in case of malfunction, cause an electric shock hazard. Generated signals do not always closely approximate those generated by bone. Surgery is required for installation of some device types. "On-again/off-again" treatment (typically fc 3 to 8 hours per day) requires active and knowledgeable, daily action by the patient or others, preferably, some built-in method to record compliance. In contrast, the present invention is compact, light in weight, inexpensive to build and use, operates at low power, is completely self-contained, requires no surgery, may be left in place for the duration of healing with only occasional attention from the patient or others, and presents no shock hazard.

- Patent.

SRS-89-0051

Licensing Representative

Westinghouse Savannah River Company

Cooperative Research Center

227 Gateway Drive

Aiken, SC 29803

$1-800-228-3843$ 
Title:

Application:

Advantages :

Abstract:

Status:

Reference. \# :

Contact :
Method and Device for Frictional Welding

Other: Industrial

A weld ring is designed to allow complete sealing by friction welding of uranium metal inside a thin, aluminum clad slug for a nuclear, reactor. The solid state weld produces a highly reliable closure which" is free from defects such as gas porosity and alloying of different metal to form. low melting point eutectics.

Patent

SRS $-90-0004$

Licensing. Representative

Westinghouse Savannah River Company Cooperative Research Center

227 . Gateway Drive

Aiken, SC 29803

$1-800-228-3843$. 
Title:

Application:

Advantages :

Abstract :
Disposal Sludge Dewatering Container and Method

Environmental Remediation
The B-12 Sand Filter Assembly provides a method for dewatering radioactive solids: The beauty of the assembly is that when the' $B-12$ is filied the vacuum hose is removed and the entire assembly is buried: $B-12$ 's and $B-25$ 's are standard containers used by the Burial Ground for many types of radioactive wastes.

Status: Patent

Reference \#: ' SRS-90-0009

Contact : .

Licensing Representative Westinghouse Savannah River Company Cooperative Research Center 227 Gateway Drive

Aiken, SC 29803

$1-800-228-3843$ 
Title:

Application:

Advantages :

Abstract :

Status::

Reference \#:

Contact :
Use of Microalgae to Remove Pollutants from. Power Plant Discharges

Environmental Remediation

The present invention relates to a process for reducing th concentration:of various types of pollutants that are introduced into open bodies of water by human or natural. action and which can result in deleterious effects on man or nature. The types of water bodies to which this proces could be applied include power plant cooling ponds and lagoons, small natural or artificial lakes, water reservoirs, and other similar bodies of water which are subject to pollution by inflowing water sources. The particular pollutants addressed by this invention.include: the nitrogen and phosphorous containing nutrients which promote the growth of excessive quantities and undesirable species of phytoplankton (microalgae) in such bodies of water resulting in a degradation of' water quality and ecosystems. This invention could also result in the removal of additional pollutants, including toxic heavy metals which are known to be accumulated by microalgae. The invention also provides. for the production of microalgae biomass as a by-product of the process; said biomass being used as a source of fuels, fertilizers. and/or higher value products.

Patent

SRS $-90-0010$

Licensing Representative Westinghouse Savannah River Company Cooperative Research. Center 227 Gateway Drive

Aiken, SC 29803

$1-800-228-3843$ 
Title:

Application:

Advantages:

Abstract :

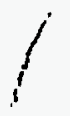

Status :

Reference \#:

Contact :
Pipe Crawler Instrument Carriage

Robotics and Remote Systems

This invention is a four degree 'of' freedom teleoperated or robotic device that is capabie of performing nondestructiv inspections inside a. pipe 12 to. 16 inches in diameter. This device is meant to be a mechanism for mounting inspection equipment on, using manual or computer controlled cylindrical coordinate motion for positioning c the instrumentation. The device, however, must be provide, a means of locomotion into the desired position for inspection. The longitudinal, rotational, and spin posittioning mechanisms, are closed loop.feedback controlle and can determine the absolute position on the inside wall of a horizontal pipe. The device is designed for servicing pipe that varies in diameter from 12 to $16^{\circ}$ inches in diameter but may be easily modified to accommodate larger diameters of pipe.

Patent

SRS-90-0013:

Licensing Representative

Westinghouse Savannah River Company Cooperative Research Center

227 Gateway Drive

Aiken; SC 29803

1-800-228-3843 
Title:

Application:

Advantages :

Abstract :

\section{Status : contact :}

Reference \#:
Optical Transcutaneous Bilirubin Detector

Other: Biomedical Applịcations
An optoelectronic instrument for measuring the level of bilirubin in the skin of infants (Infantile Jaundice) : without requiring invasive medical procedures. Infantile jaundice is common, and if undetected or untreated, can lead to brain damage: Present detection methods require blood analysis, with blood obtained through a dramatic. procedure which can raise infant stress levels. The instrument here described performs an analogous measuremen using only the differences in light reflection or absorption by two different; properly chosen skin sites;.. while minimizing interferences by skin pigments other than bilirubin.

Pateṇt.

SRS $-90-0014$

Licensing Representative Westinghouse Savannah River Company Cooperative Research Center 227 Gateway Drive

Aiken, SC 29803 $1-800-228-3843$ 
Title:

Application: ' Other: Tool Technologies

Advantages :

Abstract:

Status :

'Reference \#:

Contact:

Other: Tool Technologies

Patent

SRS $-90-0020$
Catwalk Grate Lifting Tool

This catwalk grating lifting tool is not available elsewhere. A person required to move catwalk grating can use. Cotton Bell. J. Hooks, a pair of pliers or bare hands. These methods are hazardous. The proposed method avoids back strain, potential for hand injury, and permits two people to move catwalk pieces around easily. There is a large market including construction, naval and merchant marine ships, and chemical and petroleum facilities. The tool is inexpensive to make and easily distributed to supply houses through existing distributors.

Licensing Representative

Westinghouse Savannah River Company

Cooperative Research Center

227 Gateway Drive.

Aiken, SC 29803

$1-800-228-3843$ 
Title:

Application:

Advantages :

Abstract :

Status :

Reference \#:

Contact:
Safety Harness

Other: Consumer Products
A new safety belt for construction workers is proposed tha minimizes the chance of back injuries during falls, permit use over plastic suits, and is simple and cool to wear.' I would replace a belt that is difficuit to "wear with a plastic suit, and may cause injuries to the chest and back $\because$ of a worker when arresting the workers fall.. It will alsc replace the D-ring coveralls. D-ring coveralls present a health hazard because in hot environments the employee may receive heat exhaustion. The new. belt: has passed the necessary OSHA requirements for use.

Patent

SRS-90-0022

Licensing Representative Westinghouse Savaninah River Company Cooperative. Résearch Center 227 Gateway Drive

Aiken, SC 29803 $1-800-228-3843$ 
Title:

Application :

Advantages :

Abstract :
Anti-Encrustation Coating

Other: Materials Science
A surface coating, consisting of a sheet applied to surfaces liable to encrustation by ice, concrete, paint, boiler scale or like materials, to prevent such encrustation: The sheet is composed of a tough, non-stick outer surface layer, an inner layer having variable compressibility from one part to another and other optiona layers as described. Changes in. surface pressure or loading create a flexing action which breaks away crust material as it forms.

\section{status : \\ s. \\ Reference \#:}

Contact:
Patent

SRS-90-0042

Licensing Representative Westinghouse Savannah River Company Cooperative Research Center

227 Gateway Drive

Aiken, SC 29803

$1-800-228-3843$ 
Title:

Application:

Advantages :

Abstract:

Status :

-Reference' \# :

Contact :
Sequential Power-Up Circuit

Other: Industrial
Some electrical devices, "such as motors and incandéscent lamps., draw significantly higher levels of current during the first few. seconds after starting than they do in stead operation. Switchgear and wiring for such equipment must be sized to accommodate the maximum current drawn, rather than the steady=state value. Breaking such a combined loa into several. segments and bringing each segment on-line at a slightly different time, sô that their high-demand starting periods do not overlap, can reduce the peak current level dramatically. This has a-particular advantages in computér controlled systems, where even brie power transients can interrupt vital functions. The invention consists of a simple circuit for performing sequential power-up, 'which is'logic-compatible, may be implemented on a silicon chip with only a few external components, can handle up to ten separate load segments in itts simplest form, and may be cascaded to control a larger number of segments if nécessary:

Patent

SRS-90-0037

Licensing . Represéntative

Westinghouse Savannah River Company Cooperative Research Center

227 Gateway Drive

Aiken, SC 29803

$1-800-228-3843$ 
Title:

Application:

Advantages :

Abstract:

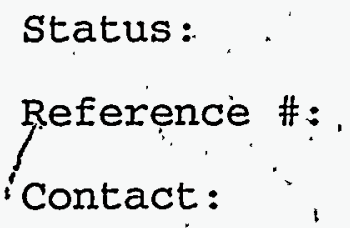

Variable Path Length Remote Optical Probe

Sensors

The device provides a variable length remote optical probe if (cell) for use in process streams and tanks. A mirrored surface is moved along an axis parallel to a lens containing two optical fibers for transmitting and receiving light for making optical measurements in the sample medium. Accurate movement of the mirror allows the cell to be used for varying sample concentration and also makes the system self referencing.

" Patent

SRS $-90-0038$

Licensing Representative

Westinghouse Savannah River Company

Cooperative Research Center

227. Gateway Drive

Aiken, SC 29803 .

$1,-800-228-3843$ 
Title:

Application:

Advantages :

Abstract :
Domestic Waste water Heat Reclaimer

Other: Industrial

Many industrial processes involving hot liquids use the combination of a heat exchanger and $a$ temperature controller, acting through a proportioning valve to regulate liquid temperature and reclaim energy used in heating the liquid. The cost of these devices' has generally prevented their use in similar domestic applications; such as washing and especially showering. Th invention consists of a heat exchanger and a mixing valve, the latter incorporating a simple and rugged temperature controllex which requires no power source other than the thermal energy. of the water. These components are designe to work together as a single system, and are rugged enough to require virtually no maintenance. Since only common materials and simple manufacturing techniques are used, th system can be made sufficiently low in cost for home installation and will typically pay for itself, through energy saving alone, in the first two or three years of us.

Status:

Patent

Reference \# :

. SRS-90-0039

contact:

Licensing Representative Westinghouse Savannah River Company. Cooperative Research Center 227 Gateway Drive Aiken, SC 29803 $1-800-228-3843$ 
Title: : Universal Fiber-Optic C.I.E. Colorimeter

Application: Other: Industrial

Advantages:

Abstract :

Accurate color measurement, or colorimetry, is needed in many fields of industry, technology and art: for instance, in assuring consistent batch-to batch colors in paint, dye goods, and metal alloys. Classical matching "by eye" is n loriger adequate. "A mathematical system of colorimetry has been developed by the International Committee on

- Illumination (C.I.E.) and proposed as a world wide standard, but instruments following this standard are prohibitively expensive for most applications. The invention consists of a combined electronic and fiber-opti method of implementing the C.I.E. system using potentially inexpensive components.

status :

Patent

Reference \#:

SRS-90-0041

contact:

Licensing Representative Westinghouse Savannah River Company Cooperative Research Center 227 Gateway Drive

Aiken, SC 29803 $1-800-228-3843$ 
Tïtle:

Application:

Advantages :

Abstract: : :

Status :

Reference \#:

Contact:
Fluid Flow Monitoring Devices

Other: Industrial

$=$

Fluid flow measurements inside of pipes can be made using many different metering devices, one of these devices is known as a venturi meter. A venturi meter is a device where the reduction of cross sectional area causes a drop in pressure and an increase in fluid velocity. The change. in fluid flow characteristics can then be used to determin the fluid flow, in a.proposed reactor cooling system it is desired to measure to coolant flow rate. The physical constraints of the proposed reactor cooling system do not allow the use of standard venturi. The meter must be removed at times during maintenance operations. This mete must also measure the flow from the inside of a pipe, or sleeve, and conduct the pressure information up the side wall of the thin walled pipe or sleeve. To accomplish thi. task a two piece venturi was designed. An annular center-body was used to. decrease the fllow cross sectional area. And.a monitoring sleeve was designed to monitor the fluid flow characteristics passing through the annular center-body configuration. CENTER-BODY (BULLET) The center-body (bullet) was designed to resemble the inverse of a standard venturi, reducing the effective flow and are from the inside out. The size and shape of the bullet depend upon the desired pressure drop and strength. of the signal. However, the shape and angle 'of the entrance and exit cones was determined to be optimal for the meter des

Patent

SRS $-90-0043$

Licensing Representative Westinghouse Savannah River Company Cooperative Research Center: 227 Gateway Drive

Aiken, SC 29803

$1-800-228-3843$ 
Title:

Application :

Advantages :

Abstract : .

Status :

Reference \#:

Contact :
Robotic End Effector

Robotics and Remote Systems

The objective of this invention is to provide a means for robot to hold NDE probes, such as ultrasonic or eddy current transducers which detect defects in metal, and position them underwater 'on a metal plate that requires examination for defects. This device rigidly holds NDE probes normal to a reactor tank wall while forcing the. probes to maintain the wall contact. The gimbal keeps the probes normal to the tank wall as long as the robot arm, t which the end effector is mounted, is within +-. 30 degrees of being perpendicular to the tank. The compliance

provides a half inch of axial travel that is spring loaded to extend. The compliance allows the robot to scan irregular surfaces by extending or retracting automatically. Position feedback from the end effector directs the robot to extend or retract its arm such that the compliance travel is maintained at its midpoint. This is accomplished in a package that is less than 3.5 inches in diameter and has an inner watertight chamber where - electronic position transducers are located.

Patent

SRS-90-0052

Licensing. Representative Westinghouse Savannah River Company Cooperative Research Center

227 . Gateway Drive

Aiken, SC 29803

$1-800-228-3843$ 
Title:

Application :

Advantages :

Abstract :

Status :

Reference \#:

Contact:
Alkaline Solution Absorption' of Carbon Dioxide Method and Apparatus

Other: Industrial

The hyuroxide concentration or $\mathrm{pH}$ of an alkaline solution can be determined by passing a gas containing carbon dioxide over the solution and measuring the rate of carbon dioxide absorption by the solution. This allows the determination of hydroxide concentration or $\mathrm{pH}$ without. having to take and analyze a liquid sample.

Patent

SRS-90-0051

Licensing Representative Westinghouse Savannah River Company Cooperative Research Center. 227 Gateway Drive Aiken, SC 29803 $1-800-228-3843$ 
Title:

Application:

Advantages :

Abstract:

Status :

Reference \#: Contact:
Thermal Manipulation of Medical Catheters

Other: Biomedical Applications

$-$

This invention proposes to use laser light transmitted via optical fibers to activate thermal elements in the types $c$ medical catheters. With this mechanism, catheters could $\mathrm{t}$ made that aré equal to or less than $1 \mathrm{~mm}$ in diameter for use in blood vessels too small to be probed with existing catheters. Catheter type could be made to bend, stretch blood vessels, take tissue samples and/or manipulate microscopic surgical tools such as scalpels.

Patent

SRS $-90-0058$

Licensing Rèpresentative Westinghouse Savannah River Company Cooperative Research Center 227 Gateway Drive

Aiken, SC 29803

$1-800-228-3843$ 
Title:

Application:

Advantages :

Abstract:

Status:

Reference \#:

Contact:
Pipe Crawler With Extendible Legs

Robotics and Remote Systems

Inspection of all reactor piping will be required in the near future. Some piping sections will require inspection internally due to physicail constraints. Commercially available inspection systems are incapable of handling large changes in pipe diameter (greater than 1-2 inches) and therefore can not be used to access all areas of SRS reactors or commercial piping systems. Using the inch-wor method of a commercial pipe crawler, modifications were made to the leg piston arrangement to allow it to easily handle large diametrical changes. Unique rearrangement of the pistonis is the noveity of the design. ADVANTAGES: Capable of traversing 12" to 24" piping. systems (12" diametrical changes). Iighter in weight-17 lbs. vs. 35-75 lbs. commercially, Simple in design-easy to maintain even if contaminated, Inexpensive-parts are easy to machine since there are no tight tolerances.

Patent

SRS $-90-0059$

Licensing Representative Westinghouse Savannah River Company Cooperative Research Center

227 Gateway Drive

Aiken, SC 29803

$1-800-228-3843$ 
Title:

Application:

Advantages :

Abstract:

Status :

Reference \#:

Contact:
Random One-of-"N" Selector.

Other: Consumer Products.

Previous methods of random sampling have relied either on taking "every Nth item",. on slow and cumbersome mechanical "selection methods such as drawing cards from a deck ", or on the generation of pseudo random numbers by a computer. Th invention provides a simple, fast electronic alternative $t$ these methods.

The invention is an electronic selection device which permits true random sampling of items for inspection or. quality testing.' Multiple randomizing factors are built i to eliminate any possibility of systematic error or

prediction of which items will be chosen. Switch settings allow selection of any "one-of- $\mathrm{N}$ ". sample proportion, from "one-of-two" (50\%) downward. Potentially compact, rugged and low in cost, and extremely simple to use, the inventic is suitable for use on the factory floor or outdoors in an weather.

\section{Patent}

SRS-90-0068

Licensing Representative Westinghouse Savannah River Company Cooperative Research Center

227 Gateway Drive

Ai-ken, SC 29803

- $1-800-228-3843$ 
Title:

Application:

Advantages :

Abstract :

Status:

Reference \#:

Contact:
Atomic Iine Emission Analyzer for Hydrogen Isotopes.

Hydirogen

Replacement of ion-beam technology by an optical.technique greatly reduces the weight, cost and complexity of the apparatus and the time needed for each analysis. This makes use of the instrument practical for on-line or. at-line industrial analyses, or for analyses. conducted in the fie'ld.

The invention represents an improved method for analyzing hydrogen samples for isotopic content. The method commoni in use requires a mass spectroscope, which is heavily, bulky and very expensive, which relies critically on the attainment of very.high vacuum levels, and which destroys samples being analyzed through conversion to an ion beam and subsequent pumping out of the vacuum system. The invention retains samples in a small electric'discharge tube, from which they can be recovered after analysis. By replacing' the ion beam with one of 1 ight, it does away wit the high-vacuum requirement, the weight and bulk of large magnets needed to'steer the ion beam, and hence with most of the system size and cost. A.side benefit of this replacement is the elimination of interference by helium-3 a decaý product of tritium; a mass spectroscope cannot readily distinguish between the two, while the optical technique is insensitive to any element except hydrogen.

Patent

SRS-90-0072

Licensing Representative Westinghouse Savannah River Company Cooperative Research Center

227 Gateway Drive

Aiken, SC 29803

$1-800-228-3843$ 
Title:

Application:

Advantages:.

Abstract :

Status :

Reference \#:. Contact:
Fiber Optic Based Hydrogen Sensor

Sensors

Several processes at the Savannah River site generate hydrogen. The operational safety requirements have specifi limits to the hydrogen concentration. This requires the monitoring of the hydrogen concentration during a dissolution. Several sensors have been tried, but they ar poisoned by Nitrogen oxides, another gas generated by the process. We have developed a sensor that will monitor hydrogen, but is not poisoned by NOx.

Patent

SRS-90-0071

Licensing Representative Westinghouse Savannah River Company Cooperative Research Center 227 Gateway Drive

Aiken, SC 29803 $1-800-228-3843$ 
Title:

Application :

Advantages :

Abstract :

Status :

Reference \#:

Contact:
Vacuum Tool Manipulator

Other: Tool Technologies
This tool was designed in conjunction with the Reactor Vacuum Tool. Its function is to move. the longer flexible hose of the vaciuum around the floor of the reactor' tank. Being able to manipulate the hose allows the vacuum to clean a large area without having to move the vacuum itsel

Patent

SRS $-90-0082$

Licensing Representative Westinghouse Savannah. River Company Cooperative Research Center:

227. Gateway Drive -

Aiken, SC 29803

$1-800-228-3843$ 
Title:

Application:

Advantages :

Abstract :

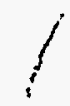

Status :

Reference \#:

Contact:
Efficient Generation of Low-Divergence Laser. Beams

\section{Other: Industrial}

Bessel beams are presently created using similar annular. slits. The invention uses a seldom-appreciated property $c$ beam, interference to create a spatial filter which is capable of transmitting roughly half the incident, light as a Bessel beam and simultaneously forming a second Bessel beam, spatially coherent with the first, from the light which is not transmitted. This offers nearly total energy conversion.

The invention is a method of converting ordinarý laser light, which normally has a Gaussian distribution of energ within the beam, into a form having a Bèssel distribution. Bessel beams have been found to have much smaller divergence than Gaussian beams (when properly focused) because destructive diffraction effects present inefficient, transforming only a few percent of the beam energy and wasting the rest. The invention offers a means of conversion with efficiency possibly approaching one hundred percent.

\section{Patent}

SRS-90,-0079.

Licensing Representative. Westinghouse Savannah River Company Cooperative Research Center

227 Gateway Drive

Aiken, SC 29803

$1-800-228-3843$ 
Title:

Application :

Advantages :

Abstract:

Status :

Reference \#:

Contact:
Microelectrode Array Voltammetry."

Other: Industrial

Using multiple working electrodes simultaneously to acquir current/voltage perturbation data and then deconvoluting the data using chemometric analysis to obtain a positive species identification.

A major limitation to stripping voltammetry is the fact: that some elements strip out at the same potential, making positive identification of an element difficult $(1,2)$. It is rare however that two elements will plate and strip at the same potentials on five different electrodes. Microelectrode array voltammetry uses a seven electrode cell: 1-reference, 1-auxiliary, and 5 working ( $C, A u ̈, P t$, $\mathrm{Ni}$, and $\mathrm{Ag})$. Stripping analysis is run on all five workin. electrodes consecutively. The resultant data is compared with stored computer data and a positive identification of the eiements in. solution is made.

Patent

SRS-90-0088

Licensing Representative Westinghouse Savannah River Company Cooperative Research Center 227 Gateway Drive Aiken, SC 29803

$1-800-228-3843$ 
Title:

Application:

Advantages :

Abstract:

Status :

Reference \#:

Contact:
Horizontal Well Insert for In-Situ Ground water Remediatic. System

\section{Environmental Remediation}

At present, the total amount of fluid entering the system can be controlled, but the amount of fluid entering the contaminant plume at each point along the length of the injection well cannot be adjusted to compensate for different local flow rates due to differences in subsurfac soil conditions. This invention provides an apparatus and method for doing this.

A gated pipe insert for the horizontal injection well of a in-situ remediation system for contaminated ground water. Each gate is equipped with a sensor to measure the amount of fluid flowing through the opening and a controller to adjust the size of the opening: The individual sensors an controllers are connected to a surface control module by any convenient mechanical, electrical, or optical linkages By comparing the individual measurements of fluid flow, the size of the openings can be adjusted to approximately equalized the amount of fluid which is injected into the contaminated plume at each gate. The gates may be controlled individually or in groups. Adjustments may be made manually, or the control module may be programmed to maintain a uniform rate of flow through each gate or group of gates. This minimizes overall treatment time and fluid wastage caused by differences in the rate of fluid flow through the system due to nonuniform subsurface soil

conditions. The insert and control module may be added tc the existing 'system' wherever pre-treatment testing indicates the presence of such conditions. Alternatively. they can be incorporated into the system and used as neede

Patent .

SRS-90-0093

Licensing Representative Westinghouse Savannah River Company Cooperative Research Center. 227 Gateway Drive

Aiken, SC 29803

$1-800-228-3843$ 
Title:

Application:

Advantages :

Abstract:

status :

Referènce \#: Contact:
Gripper Deploying and Inverting. Linkage

Other:: Industrial
This is a four bar linkage that deploys a gripper, which is described in a separate disclosure. The gripper and linkage are sub-assemblies of a reactor tool used to recover damaged sleeve housings.in SRS Reactors called an USH Gripper. Tool. The linkage translates the gripper 7 inches laterally and rotates it 180 degrees in order to properly position the gripper so that it can latch onto th' bottom of an Universal sleeve Housing (USH).

patent

$$
\text { SRS-90-00096 }
$$

Licensing Representative Westinghoüse Savannah River Company Cooperative Research Center 227 . Gateway Drive Aiken; SC 29803 $1-800-228-3843$ 
Title:

Application:'

Advantages :

Abstract:

1

status :

Reference \#:

Contact :
High-Frequency Reference Electrode

Othier: Industrial

A combination electrode of similar function, previously described by Mansfield et. al. was made up of two geometrically separate electrodes of relatively conventional form, mounted side by side. This arrangement made the electrode vulnerable to several. types of interference, as described in this. Disclosure. The invention uses a novel, coaxial geometry to eliminate thes sources of error.

The invention is a combination electrode for use in electrochemical experiments, consisting of a calomel or silver-chloride reference electrode- whose tip is surrounde by a platinum "halo" which is coupled to the reference electrode's signal lead through one or more switch-selecte capacitors. This arrangement gives superior.

high-frequency response over conventional reference electrodes, avoids sources of error whilch would be present if separate electrodes were used, and simplifies matching of the electrode to laboratory instruments (potentiostats) having various types of input circuitry.

Patent

SRS $-90-0111$

Licensing Representative Westinghouse' Savannah River Company Cooperative Research Center 227 Gateway Drive Aiken; SC 29803 $1-800-228-3843$ 
Title:

Application:

Advantages :

Abstract:

status:

Reference \#: Contact:
Fiber Optic Monitoring Device

Șensors

This transfers fiber optic switch information into a digital communication protócol that can be read by a computèr.

This is an interface between fiber optic switches and a computer that supports a standard communication protocol. The device supports a control panel composed of multiple fiber optic switches. The switch states are multiplexed. inside the device and sent out as digital data over a communication link to a computer.

Patent

SRS $-90-0123$

Iicensing Representative Westinghouse Savannah River Company:

Cooperative Research Center

227 Gateway Drive

Aiken, SC 29803

$1-800-228-3843$ 
Title:

Appliçation :

Advantages :

Abstract :

Śtatus :

Reference \#:

Contact :
Contamination Containment system

Environmental Remediation

This method is not used for preventing the spread. of subsurface contaminants. Since the system can be implemented in a much shorter time than other containment systems, it has the benefit of significant cost-savings.

A contamination containment system consists of a horizonta well placed under the containment area below the water table. Air injected into the well percolates upwards. This creates a "curtain": of low water permeability soil surrounding the contaminants. Unlike presently available concrete wall systems, it can be installed in days rather than months, resulting in significant savings in treatment time and expense.

Patent

SRS'-90-0133

Licensing Representative Westinghouse Savannah River Company. Cooperative Research Center 227 Gateway Drive Aiken, SC 29803 $1-800-228-3843$ 
Title:

Application:

Advantages:

Abstract:

Status :

Reference \#:

Contact:
Concealed-Wiring Tracer

Othér: Industrial

While employing well-known physical principles, the invention uses a novel wave form which permits very efficient energy transfer between transmitting and receiving modules. All component's are so designed as to optimize this transfer. This permits the signal. generator to be made very compact, portable and battery-powered, while the sensing coil requires no power source at all, being driven entirely by power transmitted from the generating module.

The invention is a device for tracing and marking the path of wiring concealed underground or within a buildings walls, floor or ceiling, without requiring the covering material to be disturbed: The methodi is selective; permitting (in most cases). a single, selected wire to be traced regardless of the presence of other wires and other metal objects nearby. Use of the invention would permit th. exact route of cables to be determined (or verified) at th. time of digging or building modification, and thus reduce the likelihood of tool or cable damage and the hazard of accidental electrocution.

Patent

SRS $-90-0134$

Licensing Representative

Westinghouse Savannah River Company

Cooperative Research Center

227 Gateway Drive

Aiken, SC 2.9803

$1-800-228-3843$ 
Title:

Application:

Advantages :

Abstract :

Status:

Reference \#:

Contact :
Feed Distribution Device for Glass Melter

Waste Management

This device evenly distributes slurry feed by use'of air' propellant. It aliows for control of particle size and. dispersion by varying the area through which air enters th. system as well as air flow rate. It includes a means. of cleaning any plúgs of material which accumulate during. operation. Modular construction allows the inner "operatin portion to be removed for cleaning or replacement.. The device is scaleable via adjustable parameters such as slot area, air flow rate, number of slots employed, and outlet. angle.

A device for delivering slurry feed to a glass melter has an outer housing which contains an insulating layer and provision for circulating coolant. The inner portion includes a slotted tube with multiple vertical slots surrounding a central coolant torpedo, and seven vertical stripping ribs which fit into the slots. The slurry feed enters the device between the coolant torpedo and the slotted tube. The air propellant is introduced between th slotted tube and the outer housing, passes through the slots and mixes with the slurry, resulting in globular particle distribution. Particle size and dispersion can be controlled by adjusting the exposed slot area and by cooling the air flow rate. The stripping ribs clear any accumulations of feed material when formed in the slots. All but the outer housing of the feed device can be remove for cleaning or replacement, as needed.

Patent

SRS-90-0137

Licensing Representative Westinghouse Savannah River Company Cooperative Research Center 227 Gateway Drive

Aiken, SC 29803

$1-800-228-3843$ 
Title:

Application:

Advantages :

Abstract :

Status:

Reference \#:

Contact:
Electrochemical Separation of Metal Ions Solution

other: Industrial

Quantitative and positive qualitative identification of ions in multi-element mixtures with recoverable separated products. This is:similar to: chromatographic separations. except the separatior "column" is an electrode which is mor rugged, inexpensive, easier to fabricate, and less prone $t$ failure than a packed chromatographic column. With plate and strip EC analysis in a stagnate solution cell, the species cannot be positively. identified and cannot be separated into discrete samples.

Metali ions in solution can be quantitatively separated and identified using a plate and strip method in an

electrochemical flow cell. During the plating step, the sample flows through the working electrode cell while the potential of this electrode is poised at, a negative valve. The metal ions are reduced onto the surface of the electrode. The potential of this electrode is then scanne linearly in the positive direction. As the oxidation.

potential is reached, the plated metal ions are oxidized c "stripped" off the working electrode surface. These metal' ions then pass out of the cell in a flowing stream. through an additional spectrophotometric detector for

identification. The separated fractions can be collected for further use.

Patent

SRS-90-0147

Licensing Representative Westinghouse Savannah' River Company Cooperative Research Center 227 Gateway Drive

Aiken; SC 29803

$1-800-228-3843$ 
Title:

Application:

Advantages :

Abstract:

Status:

Reference:\#: : Contact:
Reduction of Noise in Negative Ion Quadrupole Mass Spectrometry

Other: Industrial

Magnetic fields have not been previously used to separate electrons from ions in quadrupole mass spectrometry.

This invention proposes to use weak magnetic fields to prevent electrons from reaching the ion detectors in quadrupole mass spectrometers (QMS) that are operated in th. , negative ion mode. Electrons contributed a substantial background in negative ion QMS. Their,elimination would greatly improve the signal-to-noise ratio and detection limits.

Patent

SRS-90-0.157

Licensing Rèpresentative Westinghouse Savannah River-Company Cooperative Research Center 227 Gateway Drive.

Aiken, SC 2.9803

$1-800-228-3843$ 
Title:

Application:

Advantages :

Abstract:

$i$

Status:

Reference \#:

Contact :
Flow Measurement by Focused Ultrasonic Waves

Other: Industrial

The invention makes it possible to apply the "point-focus" flow-sensing method, previously limited to laser systems,. to ultrasonic flow measurement and hence to a variety of dark or turbid fluids not compatible with laser light.

The invention is a device for generating an ultrasonic signal, coupling this signal into a body of flowing liquid in such a way that the energy travels roughly parallel to the expected flow direction (for instance, along pipe) and is brought to a focus within the liquid at or near the focal point. The amplitudé and direction of such Dopplier shifted indicates the speed and direction of flow at the focal point. The sensing. device is so designed as to present only a smooth, non-obstructive surface to the flowing. liquid.

Patent

SRS-90-0170

Licensing Representative Westinghouse Savannah River Company Cooperative Research Center

227 Gateway Drive

Aiken, SC 29803

$1-800-228-3843$ 
Title:

Application:

Advantages :

Abstract :

Status :

Reference \#:

Contact:
Pulsed Laser Desorption of .Condensed Isotopic Mixtures of Molecular Hydrogen from Surfaces

Hydrogen

The major advantage of this is that a desorbed pulse of th isotopic mixture is introduced in the source as a packet. Therefore, 1 ) resolution is improved vs. any effusive method. 2) since the concentration is higher in the packet detection.is improved. 3) the pulsed method provides a wa of overcoming the "memory" problem since the background ionization can be eliminated from the signal by computer modeling.

It is proposed to design a new method for the determinatic of the isotopic ratio of $\mathrm{H} 2, \mathrm{HD}, \mathrm{HT}, \mathrm{D} 2, \mathrm{DT}$, $\mathrm{TT}$ in the air The isotopic mixture, which has been concentrated by the use of a selective permeable membrane, is condensed onto a rotating' cold finger: 'A pulsed laser beam is utilized to desorb a layer of the condensed isotopic mixture into the ionization source. Ionization of the sample is carried, ou by resonance enhanced multiphoton ionization or electrón impaçt.

Patent

SRS $-90-0178$

Licensing Representative

Westinghouse Savannah River Company Cooperative Research Center

227 Gateway Drive

Aiken, SC 29803

$1-800-228-3843$ 
Title:

Application:

Advantages :

Abstract :

Status :

Reference \#:

Contact:
Analysis of Vapor Phase Samples Using Pulsed Valves and a Pulsed Gas Discharge

Other: Industrial

Since a pulsed valve is utilized, sample consumption is minimum. Since a small amount of sample is used,. the pumping requirements of the system is reduced. Also, "memory" effects are minimized. Since this experiment is performed in the pulsed mode, the concentration of the sample during the pulse is high enough to obtain a good signal/noise ratio.

It is proposed to use a pulsed valve with an approximate 5 usec FWHM (smaller the pulse width the better) in order tc introduce the sample into the ionization source. The sample can be pure or diluted in a carrier gas (to aid the", electric discharge). The. ionization of the sample is carried out by an electric discharge through the gas pulse between the electrodes. Ions produced in the ionization source will be filtered by a mass spectrometer.

Patent

SRS-90-0184

Licensing Representative Westinghouse Savannah River Company Cooperative Research' Center 227 Gateway Drive Aiken, SC 29803 $1-800-228-3843$ 
Title: ;

Light Absorption Cell Combiring Variable Path and Length Pump

Application:

Sensors

Advantages : :

This system combines; a pump with controllable path length. There is no need for a separate feeder to the cell.

Abstract: 1 .

A cell combining a characteristic light absorption system and a pump. The light is transmitted to and from the cell with fiber optics: One of the lenses, is used as a pump piston and serves to determine the absorbency path length.

Sţatus: . Patent.

Reference \#: $\quad$ SRS-90-0199

Contact: : : Iicensing Representative

Westinghouse Savannah River Company

Cooperative Research Center

227 Gateway Drive

Aiken, SC. 29803

$1-800-228-3843$ 
Title:

Application:

Advantages :

Abstract:
Remote Monitoring and Analysis of Glass Melt Composition

Waste Management

This detector is based on a straight-forward measurement $c$ the conductivity of the liquid melt, and has the advantage that it can be based under the cold cap'

A system for on-line monitoring of the composition of DWPF glass melter is being developed by A. Schneider of the Georgia Institute of Technology (WSRC Contract AX-853025). The system relies on estimated of the melt composition frc measurements of two independent physical parameters at a. known temperature. Suitable measurements are the viscosit and specific gravity, or viscosity and electrical

resistance. Viscosity can' be computed from. measurements $c$ the velocity of rise and gas bubbles released below the surface of the melt. A bubble detector for viscosity measurement includes a bubble generator and two spaced electrode,pairs. The conductivity of the melt between eac pair is continuously monitored. The magnitude of the decrease in conductivity as a bubble passes between the electrodes is proportional to the size of the bubble; the time to pass between the two pairs of electrodes is a measure of the bubble velocity. The viscosity of the melt can be estimated from these data.

\section{Patent}

SRS-90-0198

Reference \# :

Licensing Represențative Westinghouse Savannah River, Company Cooperative Research Center

$\therefore 227$ Gateway Drive

Aiken, SC 29803

$.1-800-228-3843$ 
Title:

Application:

Advantages :

Abstract :

Status:

Reference \#:

Contact :
Nozzle Mixing Ápparatus:

Other: Industrial

No device such as this for producing an air vortex is known. The principle features of this device are its simplicity of design and ease of: disassembly for cleaning or replacement .

A new concept for mixing slurry feed with an air vortex uses two interlocking housings.. The feed flows through th center of a male housing fitted to a.female housing. Air. flows on the outside of the male housing. The surfaces of. both fittings are angled to produce a tangential swirl and a conical: convergence for fanning droplets across a melt surface. Flow vanes result from insertion of the male housing into the female housing: Both housings are shaped. to permit access for cleaning as needed. The housings can be fabricated on a 4-axis EDM wire mill. Anticipated uses include application where clogging of feed distribution devices or spray nozzles is a.problem, including air spray apparatus glass processing and distribution of slurries an other liquid or semi-liquid solutions.

Patent

SRS $-90-0204$

Licensing Representative

Westinghouse Savannah River Company

Cooperative Research Center

227. Gateway Drive.

Aiken, SC $2980^{\prime} 3$

$1-800-228-3843$ 
Title:

Application:

Advantages :

Abstract :

Status :

Reférence \#:

Contact:
Lid Heater for Glass Melter

Waste Management

$-$

Inconel 690 Pipe Resistance Heaters require a low resistance when penetrating glass melter refractory walls. Use of nickel core within Inconel pipe reduces power, reduces heat build up within the wall, eliminates need for cooling bus with water, and provides Inconel 69.0 corrosion barrier.

'Patent'

:SRS-90-0244

Licen'sing Representative Wéstinghouse Savannah River Company. Cooperative Research Center 227 Gateway Drive Aiken, SC 29803 $1-800-228-3843$ 
Title:

Application:

Advantages:

Abstract :

status :

Reference \#:

Contact:
Ultrasonic Cleaning of Interior Surface

Other: Industrial

Cleaning the interior surface of a tube by inducing ultrasonic standing waves. is not apparently. known in the art. This method represents a feasible means to utilize low cost aqueous solvents instead of chlorinated fluorocarbon solvents which are both expensive and damagin. to the earth's ozone layer.

Current methods for cleaning 20 foot long stainless steel (SST) tubes in the tritium area are unsuited to non-CFC solvents which are aqueous solutions. This invention proposes to clean the internal surface of SST tubes throug the utilization of uiltrasonic standing waves. One end of the tube is blocked off while a sonic transducer is attached to the other end. The inside of the SST tube is filled with the degreaser solution: By slightly varying the frequency of transmission of the ultrasound, a standin wave pattern could be induced within the tube which would agitate the solution and cause cavitation along the interi surface of the tube. This innovative cleaning method permits efficient and less expensive degreasing with aqueous solvents which do not affect the ozone layer.

Patent.

SRS $-90-0243$

Licensing Representative Westinghouse Savannah River Company Cooperative Research. Center

227. Gateway Drive

Aiken, SC 29803 .

$1-800-228-3843$ 
Title:

Application:

Advantages :

Abstract:

Status :

Reference \#:

Contact:
Audible Radiation Monitor

Sensors

To my knowledge, little or no work has been done in audio sensory feedback to humans for the purposes of monitoring. processes and environmental factors or for process control that relies on the human ability to monitor background noises without consciou's effort.

This invention proposes to utilize the human ability to monitor audible sounds. (background noises) without expending conscious effort. "Further, this invention proposes to mathematically map the output of a radiation detection system (in the form of radiation energy spectrum to the human audio spectrum through any of several means $t$ make a musically pleasing background sound. This pleasing background would be:played in real time to the occupants $c$ a work area being monitored by. a radiation detection syste with energy discrimination capabilities. If a change should occur in the ambient radiation environment, the occupants would perceive it as a change in the background noise without ever really having to listen to the noise consciously. The invention thus directly reduces the information overload common to visual output systems which require constant conscious attention. Other applications are envisioned for the use of these same principles in system control (e'.g. balancing'the neutron flux in a reactor) and process control (e.g: alerting operations personnel to unexpected radio nuclides or concentration changes of expected nuclides in the DWPE waste stream). Other uses in general industrial monitoring and control ar also foreseen.

Patent

SRS-90-0245

Licensing Representative Westinghouse Savannah River Company Cooperative Research Center 227 Gateway Drive

Aiken, SC 29803

$1-800-228-3843$ 
Title:

Application:

Advantages:

Abstract :

4

status :

Reference: \#:

Contact :
Method for Dissolving Delta-Phase Plutonium

Hyarogen

Use of a $2 \mathrm{M}$ HNO3-0.6M HAN - 0.1M . KF solution at 50-60 degrees $C$ for delta phase $\mathrm{Pu}$ metal dissolution has not bee documented. The HAN PROCESS alleviates problems experienced with using sulfamic acid as the dissolving: solution. A plutonium $(+3)$ solution can be produced with only $13 \%$ of the gas evolution and $40 \%$ of the waste produce by the currently used sulfamic acid solution.

Substantial improvements have been made to the process tha deals with the planned recovery of impure delta-phase." plutonium metal at SRS. The normal. SRS process involves the dissolution of the $\mathrm{Pu}$ metal in sulfamic acid, oxidatic of the sulfamate to sulfate, and solvent extraction; also involved is. the concentration, precipitation and reduction of delta-Pu metal to alpha-Pu metal. This current method of Pu dissolution, however, produces a large amount of potentially dangerous hydrogen gas, a substántial amount c pyrophoric plutonium hydride, and large amounts of sulfate waste. This innovation describes the development of a nitrate-based method for dissolving delta-phase-plutonium. The solution used to dissolve the $\mathrm{Pu}$ metal is a mixture of nitric acid, hydroxyl ammonium nitrate (HAN), and fluoride This mixture offers substantial advantages over using sulfamic acid as the dissolving solution: low gas evolution, low waste volume, no hydride sludge, and a solution that is compatible with further processing.

Patent

SRS $-90-0247$

Licensing Representative Westinghouse Savannah River Company Cooperative Research Center

227 Gateway Drive.

Aiken, SC 29803

$1-800-228-3843$ 
Title:

Application:

Advantages :

Abstract :

Status :

Keference \#:

Contact :
Dimensionally Stable Metallic Hydride

Hýdrogen

Unlike some other metal hydride compact processes; this innovation is practical, gives fast kinetics, and remains stable after many absorption/desorption cycies.

Metal hydrides, which consist of metals or metal alloys, can absorb large amounts of hydrogen gas reversibly. They are being developed for applications in hydrogen processin and energy, conversion systems. This innovation describes practical method of preparing metal hydride compacts that promote fast kinetics and remain stable after many absorption/desorption cycles.

\section{patent}

SRS-91-0028

Licensing Representative Westinghouse Savánnah River Company Cooperative Research Center

227 Gateway Drive

Aiken, SC 29803

1-800-228-3843 
Title:

Application:

Advantages :

Abstract :
Tritium Monitor

Hydrogen

This analyzer is designed to measure the tritium content c aqueous samples. It is a novel assembly of known techniques to make a variety of certifiable tritium analyzers. Water is reduced to hydrogen, the gas is separated isotopically into $\mathrm{H} 2$ and a D-T fraction. The Dfraction is analyzed for tritium, the D-T fraction can be separated further if required. The initial configuration is designed to make quality assurance and calibration analyses in support of SRS effluent stream monitoring operations:

Patent.

SRS $-91-0030$

Licensing Reprèsentative . Westinghouse Savannah River Company Cooperative Research Center 227 Gateway Drive

Aiken, SC 29803

$1-800-228-3843$. 
Title:

Application:

Advantages :

Abstract :

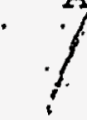

Online Fiber-optic Spectrophotometry System

\section{Sensors}

This system cán provide accurate and reliable online measurements comparable to high-quality laboratory analytical methods. A variety of high-precision spectrophotometers can be reliably adapted to harsh proces environments, while fiber optics provide a simple and cost-effective means of connecting a single spectrophotometer system to multiple points in a process. This system allows operator judgment to be programmed intc the instrument. Online blank and standard solutions provide real time measures of sÿstem noise and calibration rapid data collection allows real time sample verification. and residuals are indicative of uncalibrated interferences. and matrix effects.

A fiber-optic process analyżer system consists of a proces. analyzer, xenon arc lamp, fiber-optic multiplexer, and IBM industrial AT computer. Fused silica optical fibers connect the analyzer to process flow cells at distances up to 100. meters. The analyzer controls the sampling of each process stream and 'monitors the relative flow rate through each sampler. The multiplexer allows the analyzer to monitor up to 12 locations in series. The system is presently used to monitor the uranium and nitrate

concentrations of aqueous process streams in an SRS uraniu purification process, in addition to a reference optical fiber and an in-line uranyl nitrate standard. Absorption data from each location is fed into a model of the uranyl nitrate system for conversion into uranium and nitrate concentrations. The model also outputs a residual varianc which is used to verify the quality of the calculated results. Results are sent to a distributed control. syster which is used to run the uranium purification process. This system may be used for any application where accurate and reliable online spectrophotometric measurements of multiple process streams, or multiple locations within a single stream, are required.

Patent

SRS $-91-0039$

Licensing Representative Westinghouse Savannah River Company Cooperative Research Center

227 Gateway Drive.

Aiken, SC 29803

$1-800-228-3843$ 
Title:

Application :

Advantages :

Abstract:

Status :

Reference \#:

Contact :
Method and Apparatus for Data Sampling

Other: Industrial

All presently available radiation energy spectroscopy systems are built around the concept of integrating an incoming pulse from a detector and then converting the analog signal to a digital representation. This operation requires a certain system dead-time contribution due to th finite integration time and the. $A / D$ conversion time, as well as any delays encountered in storing or archiving the data. The present invention is based on continuous, real-time sampling at extremely fast rates above the Nyquist criteria for the frequency spectrum present in the detector output pulse. Thus it is not an event triggered system, but a continuous sampling system. Two levels of digital discrimination are applied to weed out "no-information". samples, resulting in a manageable data stream.

The invention utilizes a very high speed flash $A / D$ converter and related hardware and software to construct a radiation spectroscopy system that has no dead-time except for that inherent. in the detector itself. The related hardware consists of two forms of digital discrimination, one dealing with single bytes of data, the other dealing. with byte groupings.' The hardware also consists of a. possibly novel form of FIFO buffer (byte in, word out) and. microcomputing hardware based on very high speed DSP or Transputer components. The software consists of modules. which store data to hard disk, perform various tests and conversions on the data, and display the data for the system user. Potentially novel aspects of the software include performing "true pulse shape recovery" through Fourier and inverse Fourier transform techniques.

\section{Patent}

SRS-91-0055

Licensing Representative

Westinghouse Savannah River Company

Cooperative Research Center

227 Gateway Drive

Aiken, SC 29803

$1-800-228-3843$ 
Title:

Application:

Advantàges :

Abstract

Status::

Reference \#:-

Contact :
APPARATUS FOR ATTACHING A CLÉANING TOOL TO A ROBOTIC MANIPULATOR

Robotics and Remote Systems

The Kelly Vac Wall Attachment is the only cleaning tool developed to date that is capable of decontaminating vertical. surfaces such as walls remotely using a mobile robot.

The Kelly Vac Wall Attachment enables a mobile robot to us a standard Kelly Vac decontamination system. The robot attachment holds à Kelly Vac cleaning head in place, (1) allowing the robot gripper to easily hold on to the Kelly Vac attachment, (2) provides 10" of compliance, (3) allows wall's ard corners to be decontaminated quicker than with a manual wall tool and (4) significantly reduces radiation. exposure to personnel.

Patent

SRS-91-0064

Licensing Representative

Westinghouse Savannah River Company Cooperative Research Center

227 Gateway Drive

Aiken, SC 29803

$1-800-228-3843$ 
Title:

Application:

Advantages :

Abstract :

/ Status:

Reference \#:

Contact :
Sensors for Waste Glass Quality'Monitoring

Sensors

The redox probe is a more economically manufactured and longer life probe. The glass durability probe is the first time that waste glass can be reliably monitored as it is produced, and is a novel design resulting in relatively long life at high operating temperatures.

Waste glass quality is controlled by large homogeneous batches of slurry, and determining the composition of majc elemental constituents. Future waste processes will deal with ashes and other nonhomogeneous wastes. Electrochemica cells have been produces which permit the economic and.. instantaneous measurement of glass redox and waste glass durability. Batch preparation times are reduced and the glass quality' is monitored as it is produced.

Patent

SRS-91-0073

Licensing Representative Westinghouse Savannah River Company Cooperative Research Center

227. Gateway Drive

Aiken, SC 29803

$1-800-228-3843$ 
Title:

Application :

Advantages :

Abstract :

i

Status :

Reference \# :

Contact :
, Containment for Supercritical water Oxidation Reactor

Other: Industrial

This invention provides a containment system for supercritical water oxidation reactors that process highly radioactive or extremely hazardous materials. 'The containment system provides:- total containment of the reactor and its'contents in the event of a catastrophic failure; immediate quenching of the contents to atmospheri pressure at less than 100 degrees $C_{\text {; }}$ total isolation of th failed reactor from the process; recovery of radioactive and or other hazardous materiais from the containment system; decontamination of the containment system and the failed reactor ; and removal of the contained reactor for disposal. Note; if two or more reactors are used, a. separate containment system should be provided for each reactor.

Patent

SRS $-91-0075$

Licensing Representative Westinghouse Savannah River Company Cooperative Research Center 227 Gateway Drive Aiken, SC 29803 1-800-228-3843 
Title:

Application :

Advantages :

Abstract :

Status :

Reference \#:
Single Point Ground water Flow Monitor Based on Diffusion Salt out of a Semipermeable Cylinder

\section{Sensors}

This is an entirely new approach for single point flow monitoring in porous media. Only two other single point flow monitors have been identified in the literature or commercial sector. Both of the extant systems are based c heat. flux. One of these systems (commercial) only measure horizontal flow. The other heat based system is an experimental system. ( by Sanford.Ballard-coauthor of this disclosure) based on cylindrical heater of finite length and an array of thermocouples (similar to this disclosure)

The experimental temperature flux tool has already been built and tested successfully; there is some concern about induction of flow by the added heat. The new concentratic based probe can be designed to minimize the potential for measurement induced flows. This is the first and only known concentration flux based single point flow monitor system ever proposed:

Evaluation of' ground water quality and quantity, and proce monitoring of ground water remediation systems require detailed knowledge about the direction and rate of flow. new type of monitor to provide rapid and continuous data $c$ vertical and horizontal flow in a single bore hole has bee described. The device consists of a semipermeable membran cylinder of finite length that is filled with a solution $c$ high conductivity (salt water), a pattern of conductivity probes is placed on the surface of the cylinder. This inexpensive device is placed into the subsurface (in a bore hole or pushed into placel and backfilled. with natura materials. The concentration gradient across the semipermeable membrane will result in a flux of salt into the formation. The relative specific conductances measure by the array of specific conductance sensors in the water near the surface of the probe can be directly related to vertical and horizontal flow using analytical solutions. For example, with no.flow the concentration profile from the bottom to the top of the tool will be a bell shaped curve; vertical upward flow will result in a skewed curve with a relatively lower conductivities at the bottom of th tool and relatively higher concentrations at the top. Thi system would provide exceptionally useful data for ground water studies and remedial action control at a reasonable cost. The design of the tool minimizes the po.

Patent

SRS-91-0121

Licensing Representative 
Westinghouse Savannah River Company Cooperative Research Center

227 Gateway Drive

Aiken, SC 29803 
Title:

Application:

Advantages :

Abstract :

Status:

. Reference \#:

Contact :
Analyzer For The Study of Laser Induced Fluorescence (LIF) of Ions

other: Industrial

$-$

This analyzer used a dual penning trap ion confinement system to trap ions for study. One trap is used as an ICR mass spectrometer to isolate the ion of interest. " The second trap receives the ions selected by the first trap and confines them for optical spectroscopic studies, esp. laser induced fluorescence. A special light collection system enables a large fraction of the irradiated energy $t$ be collected. Design eliminated stray light from the irradiating beam. The ions remain trapped indefinitely, enabling multiple experiments to be carried out on the sam ensemble of ions and allowing signal averaging techniques to be utilized.

Patent

SRS-91-0139

Licensing Representative Westinghouse Savannah River Company Cooperative Research Center 227 Gateway Drive.

Aiken, SC 29803

$1-800-228-3843$ 
Title:

Application:

Advantages:

Abstract:

Status:

Reference \# :

Contact:
Filtration/Stabilization Process for M-Area Waste Treatmen (FIST Alternàte $A$ )

Environmental Remediation

Thi.s process will be used to process "IT/SF sludge in combination with $\mathrm{M}$-Area waste water slurry. It is a uniqu method of separating uranium from waste water by $\mathrm{pH}$ adjustment to minimum solubility and removal by a special pressure filter. in which nitrates are washed from all of the dewatered cake to improve integrity of the stabilized waste and achieve EPA standards for listed F-0.06 mixed waste, while generating very. little filtrate for secondary waste water treatment. Conventional equipment would .. generate more sludge from the secondary treatment. than sludge initially processed. High-volume slurry/grout treatment of mixed waste is the novel concept which requires a reliable stabilization/solidification procèss".

The planned Filtration and Stabilization facility (FIST) will process sludge from the IT/SF tanks and treat concentrated waste water slurry from M-Area production buildings as it is generated. Filter cake from the proces will be discharged into a slurry tank and mixed with water.

The slurry tank will be manually drained or pumped to a 5:0.00 gallon sluriry hold tank which will be manually., drained or pumped to a tank truck for transport to the Y-Area treatment/disposal facility. The'Y-Area treatment process stabilizes/solidifies the aqueous-based: waste in a hydrated waste form. A blend of hydraulic and pozzolanic. solids is mixed with the aqueous based waste to form a pumpable slurry/grout. Solidification takes place by incorporating water from the waste in the chemical structure of the reaction products. Stabilization takes. place by microencapsulation of the soluble contaminants in the fine pore structure of the solidified waste form; by precipitation of metal ions in the high $\mathrm{pH}$ pore fluid of the waste form; and/or by incorporation of these contaminants in the structure of the hydrated phases.

\section{Patent}

SRS $-91-0243$

Licensing Representative Westinghouse Savannah River Company Cooperative Research Center 2.27. Gateway Drive Aiken, SC 29803 $1-800-228-3843$ 
Title:

Application :

Advantages :

Abstract :

Status:

Reference \# :

Contact:
Linear Optocoupler

Other: Industrial

No presently-used device provides a pure, linear and symmetrical resistance--needed in many different circuit types to minimize signal distortion--which is electronically variable with infinite resolution, in a linear relationship with the controlling signal yet electrically isolated from it, over both time and temperature.

The invention consists of a solid-state silicon carbide: blue-light-emitting diode optically coupled with a. cadmium-sulfide photoconductive cell 'by way of 'a '. transparent but electrically-insulating medium, which may take the form of a small plate of an optical fiber of virtually any length. The output takes the form of a pure, linear and symmetrical resistance which has a very linear relationship with the input current, while a high degree of electrical isolation exists between the input an output terminals. The device should also be very stable with respect to time and temperature. These advantages are realized without requiring fine component trimming. Use of the invention would simplify circuit design.in a. wide variety of applications while increasing linearity and decreasing or eliminating signal distortion.

Patent

SRS-91-0159

Licensing Representative.

Westinghouse Savannah River Company

Cooperative Research Center

227 Gateway Drive

Aiken, SC 29803

$1-800-228-3843$ 
Title:

Application:

Advantages :

Abstract:

Status:
Reference \#

Contact:
Environmentally-Safe Compact Radiation Shield

Other: Industrial

The invention uses metallic bismuth, a virtually nontoxic and highly corrosion-resistant material, both as a gamma-ray-absorbing-material in its own right: as a metallurgically-bonded protective layer for both depleted uranium and gadolinium, permitting wider use of these materials for radiation shielding while mitigating their own possibly adverse environmental effects.

The invention consists of a radiation shielding technique which employs neither cadmium nor lead yet provides strong attenuation of gamma rays and; optionally, also of neutrons, together with a process for making small shielde containers using this technique:"

Patent

SRS-91-0165

Licensing Representative Westinghouse Savannah River Company Cooperative Research Center 227 Gateway Drive Aiken, SC 29803 $1-800-228-3843$ 
Title:

Application:

Advantages :

Abstract :

status :

Reference \#:

Contact:
High Efficiency Radiation Detector

\section{Sensors}

If the concept works, A new type scintillation detector fic - measuring nuclear radiations will be produced. The détector will be inert, non-hydroscopic, and more efficien than sodium iodide detectors (a benchmark for the industry). It would involve the doping of porous glass with lead carbonate or sulfate which scintillates when exposed to radiation.

\section{Patent}

$$
\text { SRS }-91-0166
$$

Licensing Representative Westinghouse Savannah River Company Cooperative Research Center 227 Gateway Drive Aiken, SC 29803 $1-800-228-3843$ 
Title:

Application: Advantages :

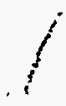

Abstract:

Status :

Reference \#:

Contact:
Process Models for Predicting Viscosity and Electrical Resistivity of Glass

Waste Management

Prior to development of these process model's, prodess control in the Defense Waste Processing Facility (DWPF) at Savannah River Site (SRS) and at other vitrification facilities. would be difficult if not impossible. These process. models were developed in order to relate readily measured parameters (melt temperature and feed composition to the viscosity and electrical resistivity of the glass. The process models relate the chemical bonding in the glas to its composition. These models are based on the number of polymerized vs. depolymerized bonds in the glass and th measured temperature dependence of the viscosity and. resistivity. The compositional and temperature dependencies of the two properties for a wide variety of glasses were shown to model as planar surfaces in three dimensional space. Mathematical equations representing these surfaces. express the glass. viscosity and resistivity as simple functions of melt temperature and glass composition.

Borosilicate glasses will be used to immobilize the high level nuclear wastes in the USA and Europe for ultimate disposal. These glasses will be produced by melting mixtures of waste and glass forming frit at 1150 degrees C and pouring the melt into'stainless steel cans for transport to a geologic repository. This innovation's " process models. will simplify the fabrication of the borosilicate glass, reliably control product quality, and ensure that Joule heating can be established during melter startup or restart. With the process models developed, th viscosity and electrical resistivity of any glass melt car be predicted based on the measurement of the composition $c$ the raw feed and the operating temperature of the melter.

Patent

SRS-91-0236

Licensing Representative Westinghouse Savannah River Company Cooperative Research Center

227 Gateway Drive

Aiken, SC. 29803

$1-800-228-3843$ 
- Title:

Application:

Advantages:

Abstract:

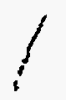

Status :

Reference \#:

Contact :
Multi-Staged Electrochemical Oxidation

Environmental Remediation

This process has never been demonstrated. In the proposed design, simple oxidation of organics with air will be, combined with electrochemical oxidation. The combination will increase the throughput of the unit while at the same time reduce operating cost's and capital equipment costs.

Ag(II) has been proven to oxidize organics rapidly, however, generation of Ag(II) consumes a good deal of powe and the capital equipment can be quite expensive when the goal of destroying large quantities of organics is considered. Most organics will oxidize to near completion in the presence of air and heat. A process is envisioned which will allow the organics to oxidize as completely as possible in the presence of air. The gases produced will then be sent to a gas-liquid contacting column where oxidation will be completed in the presence of Ag(II). Th number of $\mathrm{Ag}$ (II) ions needed to complete oxidation could $\mathrm{t}$ reduced as much as $90 \%$ or more depending on completeness $c$ oxidation in the first stage.

Patent.

SRS-91-0262

Licensing Representative Westinghouse Savannah River Company Cooperative Research Center

227 Gateway Drive

Aiken, SC 29803

$1-800-228-3843$ 
Title:

Application:

Advantages :

Abstract :

Status :

Reference \#:

Contact:
Split Drive Shaft Waste Removal Pump

Other: Industrial

This invention allows the pump drive shaft to be'separated into two sections in order to perform ne'cessary maintenanc 'on the upper half of the pump assembly. The pump uses twc types of lubricants, a grease seal, and a vapor barrier (shielding) so' that the upper 'assembly doesn't become contaminated by the waste material and therefore minimizes the exposure risk to maintenance personnel.

Pumps installed on high level waste storage tanks are, by necessity, long shafted (40 foot) vertical pumps. There are no pump's currently available for this specialized service that are designed to minimize man-rem during ' operation and maintenance and to protect the environment from contamination. The split drive shaft pump is designe to meet this requirement by allowing the pump to be:

separated into an upper and a lower assembly. The upper assembly contains the pump motor and other parts that are. likely to require frequent maintenance. The lower assembl contains the pump impeller and the lower section of the drive shaft. The two assemblies are connected by a blind slip coupling that connects the two drive shafts. The two assemblies are separated by a grease seal and shielding tc prevent contact between the waste and the upper assembly : and to prevent personnel from suffering unnecessary radiation exposure: The two assemblies are installed in a common smooth walled casing with the upper, assembly easily removable. There is no flow path of the pumped fluid to the upper end of the pump: The pumped fluid does not. rise above the normal highest level in the tank:

Patent

SRS-91-0332

Licensing Representative Westinghouse Savannah River Company Cooperative Research Centex

227 Gateway Drive

Aiken,. SC 29803

$1-800-228-3843$ 
Title:

Application:

Advantages :

Abstract :

Status :

Reference \#:

Contact :
Apparatus for Incinerating Hazardous Waste

Other: Industrial

With this shell to enclose the whole rotary kiln; the air will always leak in instead of leaking out. Therefore, an 1 ordinary kiln seal will be adequate to insure no gas insid of the kiln will leak out to the environment." This is essential for combustion of mixed wastes.

The rotary high system claimed in this disclosure is a passive and intrinsic safe system. Two inventions are claimed: 1), an enclosed shell for kiln which is pressurized. The pressure at outside of kiln is always higher than inside of kiln. 2) An emergency cooling water system which protects air pollution control equipment at downstream of the rotary kiln.

Patent

SRS-91-0369

Licensing Representative Westinghouse Savannah River Company Cooperative Research Center 227 Gateway Drive

Aiken, SC 29803

1-800-228-3843. 
Title:

Application:

Advantages :

Abstract:

!

Status :

Reference \#:

Contact:
An Autonomous Mobile Robot for Rádiological Surveys

Robotics and Remote Systems .

Current radiological surveys are performed manual ly with hand-held portable monitors or by smearing random location on the flioor and analyzing the smear. The above methods are labor intensive, cost.Iy, and inefficient. Use of an autonomous robot to perform the surveys automates the : process and greatly improves the reliability of the survey

A radiation instrument (Eberline $\mathrm{RM} 22 \mathrm{~A}$ ) is mounted on and interfaced to an autonomous mobile robot (Cybermotion K2A) to perform radiological surveys of potentially contaminate. floors. The robot scans floors at a speed of one-inch/second and stops, sounds. alarms and flashes lights, and activates a voice synthesizer when $\because$ contamination in a certain area is detected. The contamination of interest here is primarily alpha and beta-gamma. The contamination levels are low to.moderate. .

Patent

SRS $-91-0388$

Iicensing Representative.

Westinghouse Savannah River Company

Cooperative Research Center

227 Gateway Drive

Aiken, SC 29803

1-800-228-3843: 
Title:

Application:

Advantageś

Abstract:

i

,

Status :

Reference \#:

Contact :
"Closed-Field" Capacitive Proximity Sensor

Sensors

No known capacitive sensor uses a "closed" detection field

Conventional techniques for measuring force, displacement and pressure usually rely on strain gauges, which require high-precision voltage supplies and produce low-level analog outputs at high impedance. Capacitance is potentially the most versatile technique for proximity sensing, but commercial sensors create an "open" field which requires detection current to return through the environment; such devices are quite sensitive to outside influences, including.electromagnetic noise. The inventic is a capacitive sensor which creates a "closed" detection field in. which current circulates among two or more (preferably three) sets of plates and requires no external return path, making operation much more reliable and less dependent on outside factors, and whose output is a variable-frequency, logic-level pulse train which is easil interfaced with a computer. or process-control device. Applications to proximity, displacement; force and pressur measurement are described.

Patent

SRS-91-0446

Iicensing Representative Westinghouse Savannah River Company Cooperative Research Center

227 Gateway Drive

Aiken, SC 29803

$1-800-2.28-3843$ 
Title:

Application:

Advantages :

Abstract :

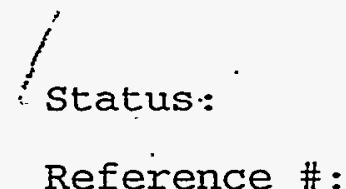

Contact:
Dropping Electrolyte Electrode

Other: Industrial

No other liquid electrolytic electrodes are known to be used in this manner. Currently mercury, which is a liquid metal, is used as an electrode but Hg presents disposal; a well as possible health problems.

This invention utilizes an electrolytic solution as an electrode to make a quantitative analysis of compounds in an aqueous solution. The electrolyte solution is immiscible with the liquid solution being analyzed and is dropped at a known rate with a known surface volume. Thus when current is passed through the solution, the electrochemical interaction between the electrode and groups in the solution can be calculated and certain measurements and/or properties can be established.

Patent

SRS $-91-0444$

Licensing Representative Westinghouse Savannah. River Company Cooperative Research Center. 227 Gateway Drive

Aiken, SC 29803

$1-800-228-3843$ 
Title:

Application:

Advantages :

Abstract :

Status :

Reference \#:

Contact :
Pipe Crawler with Suspension System

Robotics and Remote Systems

The addition of the suspension system to the Pipe crawler eliminated some problems found in the present design. The springs allow the Pipe Crawler to use a much longer stroke length because it keeps the back end of the crawler. centered in the pipe. The longer stroke length makes the upgraded Pipe Crawler more versatile than the present design: No such suspension system existed previously whic would provide the longer stroke length.

The proposed pipe crawler design is an upgrade of the Pipe Crawler Previously designed by the inventor. The design incorporates spring suspension system which allows the pip crawler to flex within the pipe. This allows a much longer stroke length, helps keep the back end of the crawler center in the pipe; and prevents the extension stroke from forcing the crawler feet to slip on the pipe wall.

Patent

SRS $-91-0485$

Licensing Representative

Westinghouse Savannah River Company

Cooperative Research Center.

227 Gateway Drive

Aiken, SC 29803

1-800-228-3843 
Title: Down Hole Optical Probe

Application: - Sensors

Advantages: $\quad$ Compact fiber optic probes designed to function with soil packed around it.

Abstract: A device has been constructed to measure the optical absorbency or fluorescence of underground fluids or gasses in-situ in wells or refilled, packed bore holes. This wil allow real-time, virtually undisturbed monitoring of migration of chemicals and dyes in soils.

Status :

Patent

Reference \#:

SRS $-91-0504$

Contact :

Licensing Représentativé Westinghouse Savannah River Company Cooperative Research Center 227 Gateway Drive

Aiken; SC 29803 .

1-800-228-3843 
Title:

Application:

Advantages :

Abstract :

Status:

Reference \#:

Contact:
Solution Assay Möitor for Analyzing Small Samples of 235Sensors

Gamma rays from a reference source are collimated to avoid: absorption by the sample in the detector well. Since sample masses are small, minor self-attenuation correction are calculated from chemical composition data rather than determined in separate transmission measurements.'

This invention is a solution assay monitor which uses a high-efficiency germanium well detector to analyze small samples. (7. $\mathrm{mL}$ ) for $235-\mathrm{U}$ gamma-rays.

\section{Patent}

SRS-92-0036

Licensing Representative Westinghouse Savannah River Company Cooperative Research Center 227 Gateway Drive

Aiken, SC 29803 $1-800-228-3843$ 
Title:

Application:

Advantages :

Abstráct

Status :

Reference \#:

Contact :
Bioremediation of Contaminated Ground water

Environmental Remediation

The use of horizontal well's to supply nutrients to promote bioremediation, the use of' methane as a nutrient to promot microbial growth and enhance bioremediation capabilities.

Horizontal weils can be used to supply nutrients, such as methane, to promote microbial growth and soil

decontamination. to indigenous soil bacteria capable of

degrading organic soil contaminants such as

trichloroethane. Such bioremediation offers the advantage that the contaminants are reduced to. simple compounds such as water, carbon dioxide, and chloride which do not requir. additional degradation. - Low concentrations of methane, $4 \%$ of the volume of air are blown under pressure into the lower of two horizontal wells. A vacuum is applied to the upper well, to promote the flow of air/methane through the vadose zone. pulsing of the methane will increase the efficiency of the process by limiting competition between . methane and TCE for the active sites on degradative enzyme

Patent.

SRS $-92-0047$

Licensing Representative Westinghouse Savannali River Company Cooperative Research "Center

227 Gateway Dirive

Aiken, SC 29803

$1-800-228-3843$. 
Title:

Application:

Advantages :

Abstract : .

Status:

Reference \#:

Contact:
Catalyzed Absorption of Hydrogen Using a Porous Glass

Hydrogen

Combining the properties of a catalyst with a porous glass will produce a matrix with an improved ability to store an recover hydrogen.

A very large amount of internal surface area can be produced by the use of sol-gel methods. This internal surface area of the porous glass matrix does not absorb. significant amounts of hydrogen by itself. However; when small amount of catalyst, such as nickel, platinum, lanthanum, or lanthanum-nickel-aluminum alloys, is incorporated into the porous structure, the surface can absorb about 18 by weight of hydrogen, or 200 liter. (STP)/liter volume of glass. The absorption is reversible The absorbed hydrogen can be recovered by heat or evacuation. Potentiai uses for the catalyzed glass includ hydrogen storage and hydrogen recovery from gas mixtures

Patent

SRS $-92-0156$

Licensing Representative

Westinghouse Savannah River Company

Cooperative Research Center

227 Gateway Drive

Aiken, SC 29803

$1-800-228-3843$ 
Title:

Application:

Advantages :

Abstract :

Status :

Reference \#:

Contact :
Method for Verification of Constituents of a Process strea Sensors

This invention provides an on-line method for qualitative and quantitative identification of $\mathrm{CW}$ agents prior to thei introduction to disposal systems without manual collection of samples and subsequent laboratory analysis, and without the associated time délay.

Chemical weapón's (CW) agents may be monitored remotely by fiber-optic near-infrared spectrophotometry. Determinatic of the identity of a $\mathrm{CW}$ agent prior to its introduction tc a kiln or other disposal system is a key to international: treaty verification: By pumping the agents through a quartz-windowed cell connected by fiber op'tics to a remote spectrophotometer and computer, their. identity can by confirmed prior to introduction to the disposal system: '. Through the use of a set of calibration data and an accurate measurement of the flow through the cell, quantitative as well as qualitative information may be obtained by this method. From a safety standpoint, this method would reduce the need for manual sample collection. and laboratory analysis and the associated risk of worker exposure to deadly,CW agents. On-Iine analysis can provid real-time data without the time delay associated with . manual sample collection and subsequent laboratory analysi

Patent

SRS $-92-0176$

Licensing Representative Westinghouse Savannah River Company Cooperative Research Center 227 Gateway Drive

Aiken, SC 29803

$1-800-228-3843$ 
Title:

Application:

Advantages :

Abstract:

Status :

Reference \#:

Contact:
Helium Probe to Discover Leak Location in Underground Wast 'Line.

Sensors

Ability to quickly locate and determine the approximate location of a.leak in an underground line.

This allows for the use of a helium sniffer probe to detec pipeline leaks and eliminates the need for excavation of large portions of a. pipeline. The tool consists of a fast sniff probe attached to tubing. The tubing is attached tc a helium leak detector.

Patent

SRS $-92-0263$

Licensing Representative.

Westinghouse Savannah River Company

Cooperative Research Center

227 Gateway Drive

Aiken, SC 29803 .

$1-800-228-3843$ 
Title:

Application :

Advantages :

\section{Abstract :}

Status :

Reference \#:

Contact:
Compact Digital Electronic Bone-Growth Stimulator

Other: Biomedical Applications

Bone-healing electrical. wave forms are not known'to have been generated previously by all-digital circuitry. The elimination of analog components minimizes parts count, thus increasing reliability while decreasing the size and cost of the assembly. Digital circuit generation under crystal control also provides more accurate timing, and more efficient. use of power.

A compact, battery-powered circuit module which generates. an electrical wave form consisting of an intermittent puls train simulating the piezoelectric response of human bone under stress. Electrical signals of this type have been shown to accelerate bone growth, especially in the healing of fractures, and to prevent or reverse the development of osteoporosis; some acceleration, in the healing of soft tissues has also been observed. Unlike an earlier implementation, the present invention uses all-digital technology already highly developed to make digital watche and could readily be fabricated. on a single logic chip. Digital watch and bone-healing functions could be combined in a single unit, if desired, and share the same timing crystal.

Patent

SRS-92-0282

Licensing Representative Westinghouse Savannah River Company Cooperative Research Center 227 Gateway Drive

Aiken, SC 29803

$1-800-228-3843$ 
Title:

Application :

Advantages :

- Abstract:

Status :

Reference \#:

Contact :
P-Scan Carriage

Robotics and Remote Systems

This new design utilizes the Y-arm off of a P-Scan scanner allowing the use of multiple probes as opposed to the single articulated probe of the previous design. Using.th $Y$-arm also increases the axial motion by $2 \mathrm{X}$. In the new design the entire front end of the carriage rotates as opposed to a rotating mounting block in the center. These changes dramatically reduce the complexity of the device and are novel improvements.

This device is an ultrasonic internal pipe inspection carriage using components off of a commercial external inspection scanner. It is a complete redesign of a prior. prototype. It is much simpler in design, easier to manufacture, operate and maintain, and has been made dramatically more reliable than the previous model.

\section{Patent}

SRS $-92-0324$

Licensing Representative Westinghouse Savannah River Company Cooperative Research Center 227 Gateway Drive.

Aiken, SC 29803

$1-800-228-3843$ 
Title:

Application:

Advantages :

Abstract :

Status:

Reference \#:

Contact :
Spectrophotometric Temperature Sensor

Sensors

This invention relies. on shifts in the absorbency spectra of materials to measure temperature. Because this

temperature sensor's response is optical, not electrical, the signal is unaffected by stray electromagnetic fields. Further, the ceramic/glass insulators used in the manufacture and sensors in this probe do not conduct heat from the point being. measured, making the probe more accurate in a process/material with low heat capacity.

This invention is a fiber optic probe capable of accuratel measuring temperatures in the presence of electromagnetic fields which interfere with:thermocouple operation. The probes depend on shifts in the absorption spectra of. optically stable materials to measure temperature accurately over a wide range. In addition, heat transfer away from the measurement point is reduced because of the low thermal conductivity: of the glass/ceramic materials used in probe manufacture. The calibration process for th spectrophotometer makes variations in probes inconsequential and eliminates the need to calibrate each probe individually, thereby saving considerable expense incurred in individually calibrating probes? This device has a large range of applications because the sensor's temperature range and accuracy can be optimized by careful selection of the temperature sensitive materials present i the probe.

Patent

SRS $-92-0350$

Iicens̀ing Representative Westinghouse Savannah River Company Cooperative Reșearch Center $227^{\circ}$ Gateway Drive

Aiken, SC 29803

$1-800-228-3843$ 
Title:

Application:

Advantages :

Abstract :

1

Status :

Reference \#:

Contact :
Radiation Spectroscopy by Image Analysis Means

Other: Materials Science

All existing radiation spectroscopy techniques are based $c$ the accurate energy determination of each.pulse that can t obtained from the detector. The invention constructs' an energy spectrum without determining the energy of any of the detector pulses. Further, it is able to digitally reduce compton scattering in the spectrum by image analysi methods to reveal spectrum peaks previously made invisible by the Compton scattering.

The invention applies sampled data and image analysis techniques to the field of radiation spectroscopy. It differs from SRS-91-055 in that once the detector output. $i$ digitized into a continuous stream of $A / D$ readings, the samples and time information are used to create a three dimensional spectrum with major axes for time and amplitud and a third axis that registers the number of occurrences of a given time-amplitude combination. This $3-D$ map is. image enhanced to make more visible any repetitive wave forms that are present. Since only repeated. occurrences of the same shape wave form are enhanced, the randomly distributed shapes of Compton events in the detector are filtered out of the spectrum, leaving only th real energy peak wave forms. . The invention differs from.a other known radiation spectroscopy techniques in that it. does not determine the energy of any individual detector pulses in order to construct an. energy spectrum.

Patent

SRS $-92-0418$

Licensing Representative Westirighouse Savannah River Company Cooperative Research Center 227 Gateway Drive Aiken, SC 29803 .1-800-228-38.43 
Title:

Application:

Advantages :

Abstract:
Representative Geometry Phantom (we call it the "RG" or "SRS" plantom for short)

Other: Industriai

This invention incorporates an angled front face and guide plates for the detectors; no other phantoms, to our , knowledge, have this feature.

This invention is an innovation on phantom design. A "phantom" is a representation or substitute for a person, used in radiation detection measurements for quality assurance blank and.source counts. Current designs for phantoms used in lung counting applications are flat. Thi does not allow:easily reproduced positioning, nor does it mimic the shape of the human body: the phantom is supposed to represent., our phantom design incorporates an angled front face (and guide plates) to allow reproducibility of detector placement, and to more appropriately model the. shape of the human torso.

Status: Patent

Reference \#: .. SRS-93-0021

Contact :

Iicensing Representative

Westinghouse Savannah River. Company

Cooperative Research center

227 Gateway Drive

Aiken, SC 29803

$1-80.0-228-3843$ 
Title:

Application:

Advantages :

Abstráct:

/status:

Reference \#:

Contact :
Fiber Optic Probe Having Fibers with Endfaces Formed for Improved Coupling Efficiency

\section{Sensors}

Other fiber optic probes rely on overlap of their light cones at far distances from the probe tip. If samples are opaque or highly scattering almost no signal is returned. Also a sample solution to optical crosstalk between fibers has demonstrated.

This method of manufacturing fiber optic probes increases the light coupling efficiency for scattering and opaque sample by about a factor 5 over conventional methods. By polishing or cutting a bundle of two or more fiber optics at specific angles from their optic axes, the optimum distance for maximum coupling efficiency can be adjusted.

Patent

SRS-93-0086

Licensing Representative Westinghouse Savannah River Company Cooperative Research Center

227 Gateway Divive

Aiken, SC 29803

$1-800-228-3843$ 
Title:

Application :

Advantages:

Abstract :

Status :

Reference \#:

Contact:
Conveyor with Rotary Airlock Apparatus

o'ther: Industrial

No other form of continuously-acting airlock, other than the primitive form represented by a revolving door (used a .. an illustration in the Disclosure), is known to exist.

Many industrial and construction processes, space and undersea exploration require objects to pass between areas of widely differing atmospheric pressures' or compositions. Airlocks are used to prevent gas flow, mixing or cross-contamination between such areas. A conventional airlock consists of a. small chamber having two doors on opposite sides, only one of which can be open at a time; a a result, material can pass through only discontinuously, in batches limited by the size of the airlock. This presents a disadvantage in many applicattions; especially i manufacturing, where materials or parts must be collected into batches for passage through the lock, then dispersed. again into streams on its further side: The invention is a rotating, continuously-acting airlock by which continuous streams of material can be passed from one atmosphere to another by means of a conveyor belt.

\section{Patent}

SRS-93-0104

Licensing Representative Westinghouse Savannah River Company: Cooperative Research Center

227 Gateway Drive

Aiken, SC 298.03

$1-800-228-3843$ 
Title:

Application:

Advantages :

Abstract :

Status :

Reference \#:

Contact:
Laminar-Flow Air Tunnel for Container Leakage Testing Usin $\therefore$ a Tracer Gas

\section{Other: Industrial}

The use of perfluorinated tracer gases in 1008 package lea inspection offers many benefits. In the past, however, th long, per-sample delays in tracer-gas detection and the hig. rate of package testing needed by the food industries have made this approach impractical. The invention disclosed here, building upon others described in accompany. Disclosures cited within, provides a means for doing this quickly and reliably.

Millions of dollars are presently spent every year by the Americal Food processing industry to ensure food product safety. Leak detection is necessary to ensure that microbial contamination has not occurred after sealing. Testing presently used to identify microleaks in food. packages is destructive. Nondestructive means would offer better precision, more consistency, better day-to-day reliability, and the ability to evaluate every package produced rather than just a small sampling: The invention is a device for use in nondestructive, $100 \%$ food package leak detection using trace levels of a nontoxic perfluorinated tracer gas introduced into packages, and consists of a tunnel employing reduced pressure and lamina flow to draw the tracer gas out through any existing leaks yet retain it in the immediate vicinity of a leaking. package until it can be detected, and to reject or divert any leaking package automatically.

\section{Patent}

SRS $-93-0122$

Licensing, Representative

Westinghouse. Savannah River Company

Cooperative Research Center

227 Gateway Drive

Aiken, SC 29803

$1-800-228-3843$ 
Title:

Application :

Advantages :

Abstract:

Status :

Reference \#:

Contact:
Process for Removing and Detoxifying Cadmium from Scrap Metal

Other: Industrial

While most of the steps described are well-known in other areas, they are not known to have been used together for removing and detoxifying cadmium from scrap metal. The superiority of amionium bicarbonate as an alternative to ammonium nitrate in cadmium extraction does not appear to have been recognized previously. Alsso, "Goldenrod"-type. compositions are not. known to have been previously propose as means of disposing safely of cadmium-bearing waste.

Cadmium i's a rare but extremely useful metal, with . applications in corrosion prevention, soldering, energy storage, and the nuclear industry. As a result, much scrap metal contains significant amounts of cadmium.

Unfortunately, cadmium is volatile as the metal, soluble i typical ground water as a complex ion, and highiy toxic in either form. This makes it difficult either to reprocess or to dispose of scrap containing cadmium. The problem is compounded in the nuclear industry, where cadmium-bearing scrap may also. be radioactive. The invention consists of a series of processing steps whereby cadmium present in scra metal of almost any type may be separated out and rendered into an insoluble form which will likely be discardable as nonhazardous or, at worst, as rädioactive but nontoxic. waste.

Patent

SRS-93-0169

Licensing Representative Westinghouse Savannah River Company Cooperative Research Center

227 Gateway Drive

Aiken, SC 29803

$1-800-228-3843$ 
Title:

Application:

Advantages :

Abstract:

Status :

Reference \#:

Contact:
Gasket and Snap Ring Installation Tool

Other: Tool Technologies.

This tool installs gaskets and snap rings into piping connectors without handling the gasket, ring, or pipe.

Installation of gaskets and snap rings on pipe joints of piping which transport radioactive waste exposes personnel to radioactive contaminants. This tool minimizes personnel exposure to radiation and contaminants. A typical gasket . and snap ring. installation is depicted in figure 1. The exploded view of figure 2 clarifies the relationship of th parts. Figures 3, 4, and 5 show the installation tool and its construction. Figures 6 and 7. demonstrate. the tools operation. First, the snap ring is compressed into the groove of the gasket plate. The gasket is then inserted onto the face of the gasket plate (figure 6). The gasket is held in place by the raised surface of the gasket plate Once the gasket and snap ring are loaded onto the plate, the assembly is inserted into the open end of the piping . connection (figure 7). Then the removable 1/2" pipe is slid over the 1/4"-pipe and forced against the push plate. The push plate travels about $1 / 4 "$, forcing the snap ring out of the groove. The snap ring springs into the groove of the piping connector, thus securing the gasket in place The tool is then removed.' Figure 8 shows an exploded vie of the tool, gasket, ring, and pipe to clarify the relationships of the parts during assembly.

Patent

SRS-93-0192

Licensing Representative Westinghouse Savannah River Company Cooperative Research Center

227 Gateway Drive

Aiken, SC 29803

$1-800-228-3843$ 
Title:

Application :

Advantages :

Abstract:

Status : :

Reference \#:

Contact:
Flexible Pipe Crawler with stabilizing Mid Section .

Robotics and Remote Systems

This pipe crawler is distinguishable from other pipe crawlers becaúse' it is designed with a mid-section, with a two axis gimbal at each end to allow the end plates of the, crawler to pivot independently. The mid-section forces th. gimbals to remain centered in the pipe; preventing misalignment.

This pipe crawler design improves upon the Pipe Crawler with Suspension System design previously submitted. The. problem addressed by the Flexible Pipe Crawler With Stabilizing Mid-Section was that the previous pipe crawler would sometimes become immobilized while maneuvering through the piping system. The gimbal, which allows the end plates of the crawler to pivot wi.th respect to one another, would become off-centered. Due to the joint misalignment, the pipe crawler would not be able to pivot properly, causing it to bind when encountering, a piping elbow in the opposite direction. To eliminate the misalignment, the proposed pipe crawler:is designed with a mid-section, with two axis gimbal at each end. The mid-section forces the gimbal to remain centered in the pipe.

Patent

SRS $-93-0,252$

Licensing Representative Westinghouse Savaninah River Company Cooperative Research Center 227 Gateway. Drive Aiken, SC 29803 $1-800-228-3843$ 